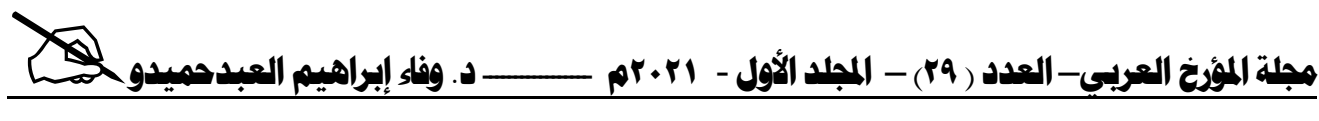

\title{
أبرز أعلام سيناء في العصور الوسطى
}

د/ دفاء إبراهيم العبد حميدو

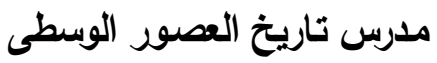

بكلية الآداب - جامعة العريش العيطي

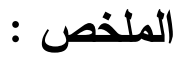

لعب سكان سيناء في العصسور الوسطى دورًا مهمَّا في تقدم الحضـارة المصـرية،

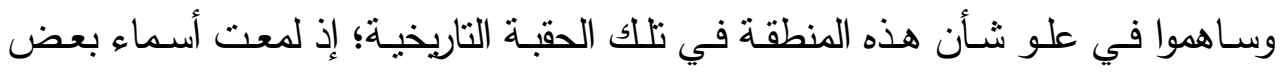

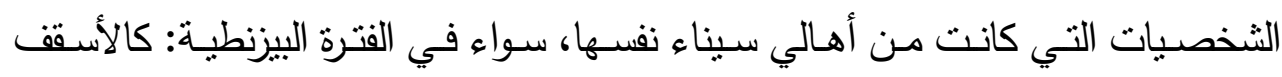

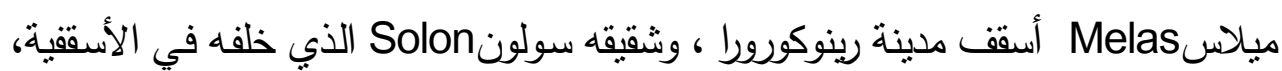
أو بعض الثخصيات في الفترة الإسلامية: كالثشاعر والفقيه أبو العباس أحمد بن إبراهيم

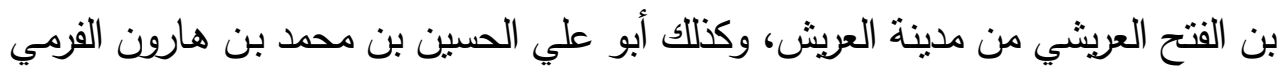

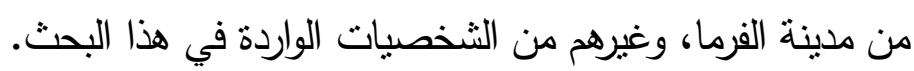

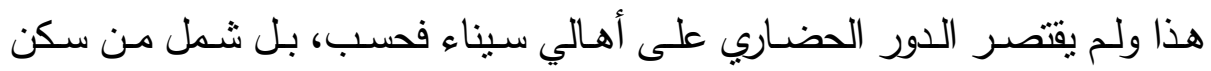
وعاث في تلك البقعة الفسيحة، فبرزت أسماء بعض الثخدي الثخصيات التي عاثتت في سيناء،

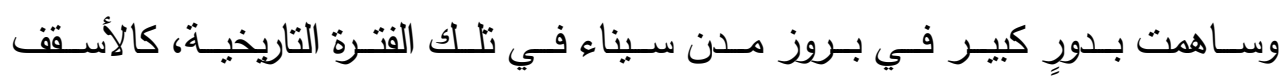

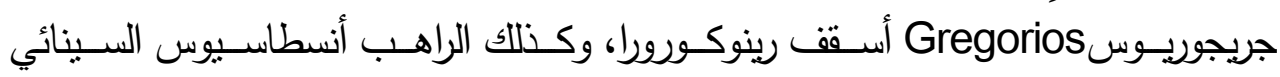
Anastasius of Sinai

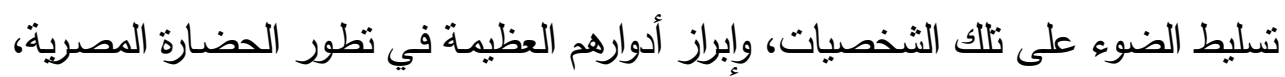
وهذا ما يسعى إليه هذا البحث.

\section{Abstract}

Outstanding Figures in Sinai in the Middle Ages

In the Middle Ages، The inhabitants of the Sinai played an important role in the progress of the Egyptian civilization، Among these figures who were from the people of Sinai itself in the Byzantine period، Bishop Melas، Bishop of Rhinokoroura، and his brother Solon who succeeded him in the episcopate، Or 
some personalities in the Islamic period such as the poet and jurist $\mathrm{Abu} \mathrm{Al-}$ Abbas Ahmad Ibn Ibrahim Ibn Al-Fath Al-Arishi from the city of El- Arish، as well as Abu Ali Al-Hussein Ibn Muhammad Ibn Haroun Al-Farmi from the city of El-Farma.

The civilized role was not limited to the people of Sinai، but also included those who lived in this area، Like Bishop Gregorios، Bishop of Rhinokoroura ، the monk Anastasius of Sinai، one of the monks of the Monastery of Saint Catherine،and others. It was necessary to shed light on these personalities، and to highlight their great roles in the development of Egyptian civilization.

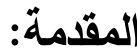

لم تكن سيناء في العصور الوسطى مجرد صحراء جرداء تتخللها الوديان وتعترضها الجبال ويقطنها البدو الرُّحل الذين غلب عليهم الجهل وقلـة الحيلة، بـل لعب سكانها دورًا مهمًّا في تقدم الحضارة الإنسانية، وأسهموا في علو شأن الثخصية المصرية في تلك الحقبة

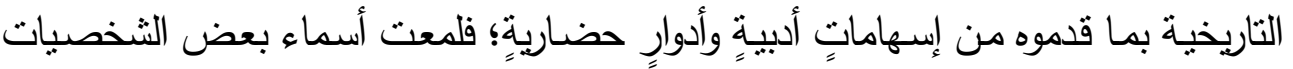
التي كانت من أهالى سيناء نفسها، وبعض الأعلام التي جاءت للسكن في سيناء، سواء

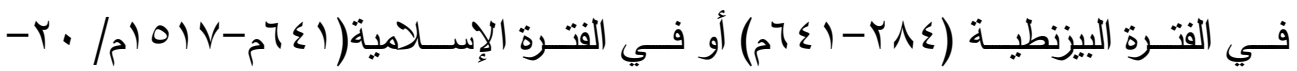
r Y وه)، فأسهووا جميعًا بدورٍ كبير في بروز مدن سيناء في تلك الفترة التاريخية، وتركوا

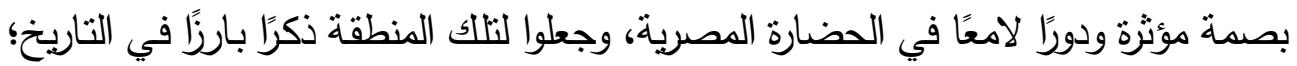
لذا كان من الضـروري تسليط الضوء على أبرز تلك الثخصيات، والكثف عن أدوارهم العظيمة في تطور الحضارة المصرية، وهذا ما بسعى إليه هذا البحث. ولم أتتاول في هذا

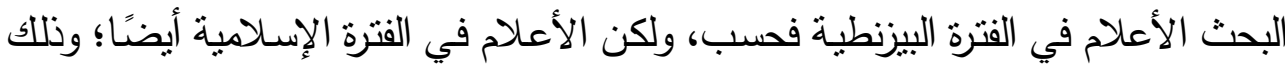

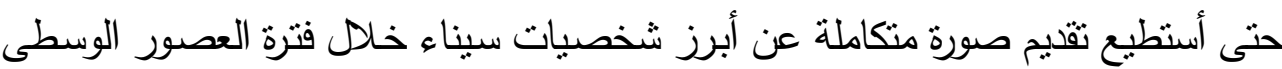


بأكملها، وأوضح كيف أن أبناء سيناء ظلاوا يسهمون في تقدم العلم حتى العصر الإسـلامي أيضًا وليس في العصر البيزنطي فحسب.

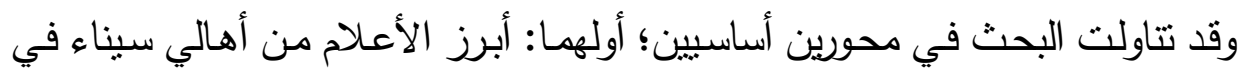

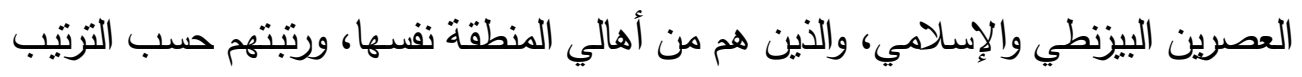

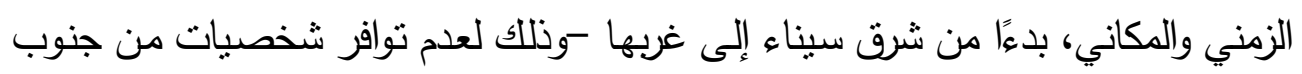

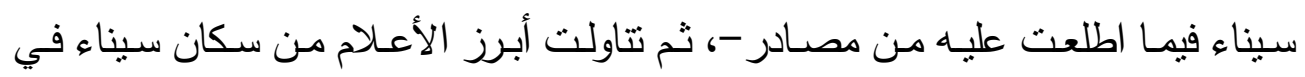

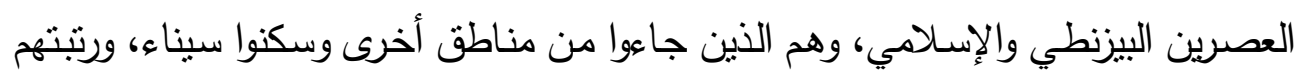

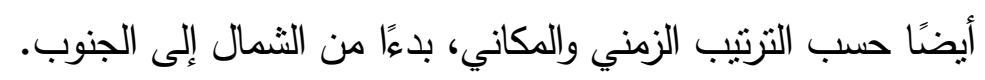

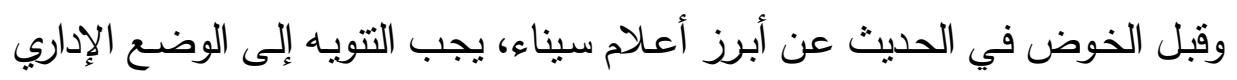

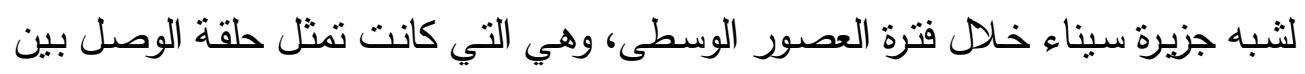

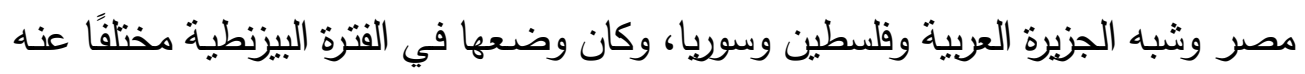

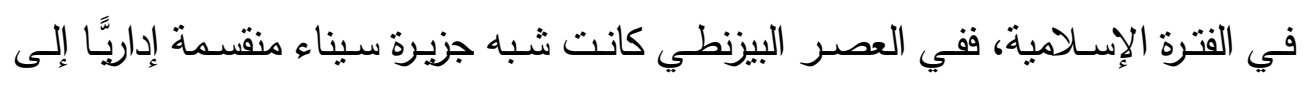

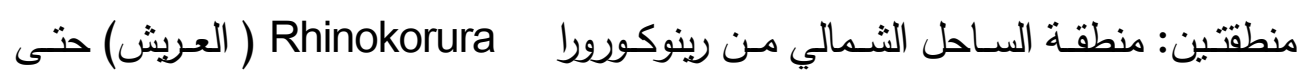

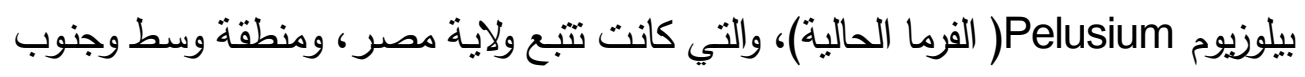

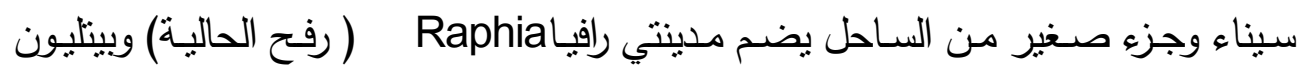
Bitylion

(1) Hieroclis, Synecdemvs Et Notitlae Graecae Episcopatvvm, ed. G. Parthey , Berolini,1866 p.48;Georgii Cyprii, Descriptio Orbis Romani, ed.H. Gelzer, Lipsiae,1790, pp.35,51-2.

Cf.also, Herbert Verreth, The Northern Sinai From The 7th Century BC Till The7th Century AD.A Guide to The Sources, 2vols. , Leuven, 2006, vol.1, pp.67-8.

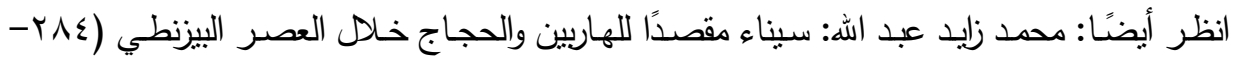

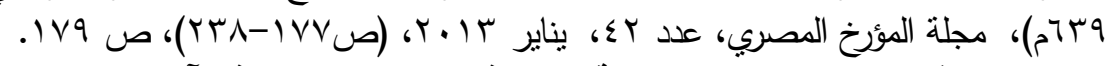
- - عن موقع مدن سيناء، انظر خريطة سيناء في العصر البيزنطي في آخر البحث. 
في العصر الإسلامي بأكملها أو ماعدا رفح تتبع مصر الإسلامية(')، وعلى الرغم من أن

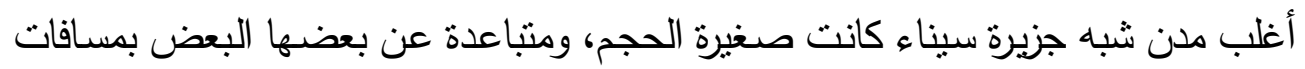

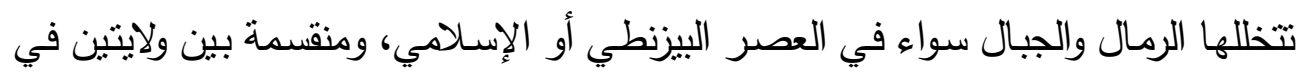

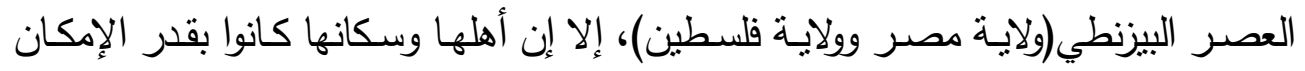

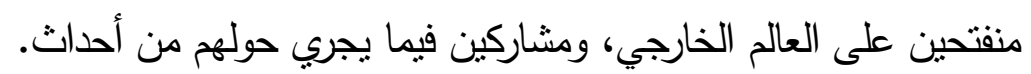
1- أبرز الأعلام من أهالي سيناء في العصرين البيزنطي والإسلاهي:

لقد برزت أسماء بعض أهـالي سيناء خـلا الفترة البيزنطية والإسـالامية ولعبوا دورًا

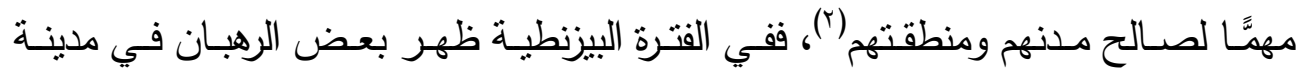

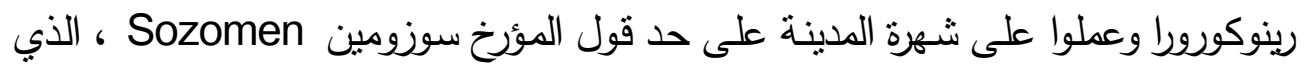

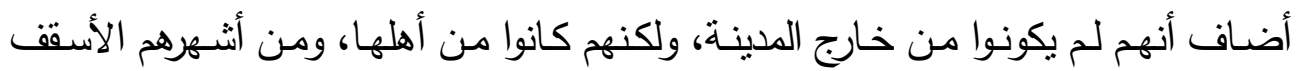

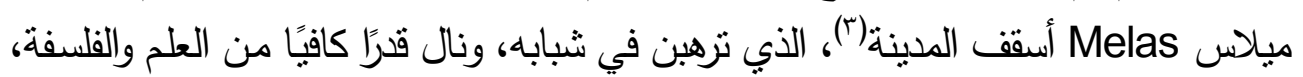

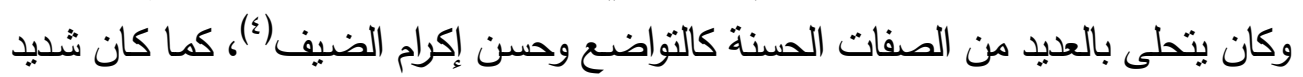

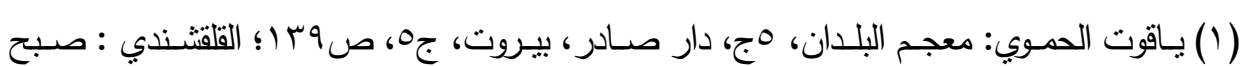

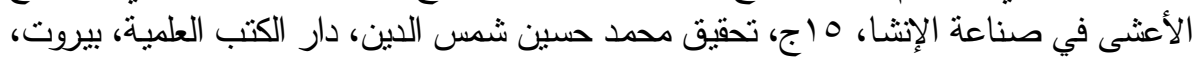

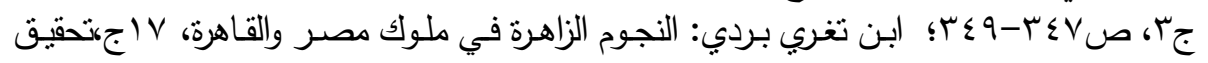

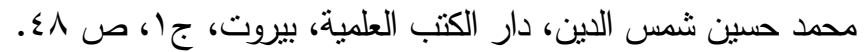

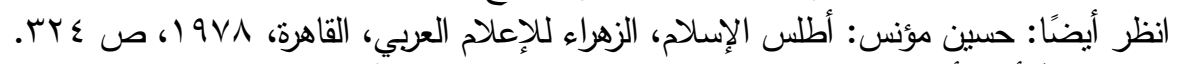
(r) انظر قائمة أبرز أعلام سيناء في العصور الوسطى في الملحق آخر البحث.

(3) Sozomenus, Church History from 323-425, in Nicene and Post-Nicene Fathers: Second Series Socrates, Sozomenus Church Histories, Tras. C. Hartranft, 14 vols., ed. Philip Schaff, New York, 2017, vol. 2, p. 369 ; Sozomen, The Ecclesiastical History of Sozomen, tr. E. Walford, London, 1855, p.296.

Cf. also, Herbert Verreth, Northern Sinai, p.288-90; lina Eckenstein , A History of Sinai, Reprint,Cambridge University Press, Cambridge, 2018 , p. 100 .

(4) Sozomenus, Church History , p. 369; Sozomen, Ecclesiastical, p.297. 


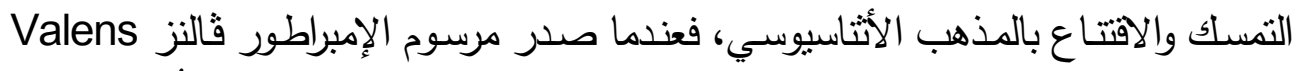

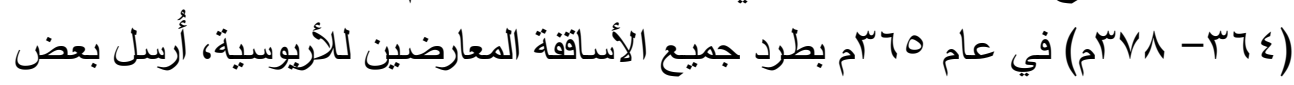

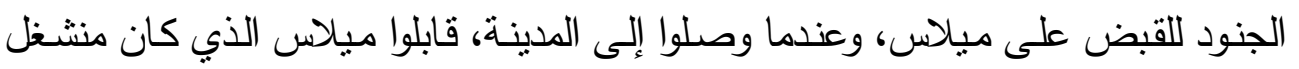

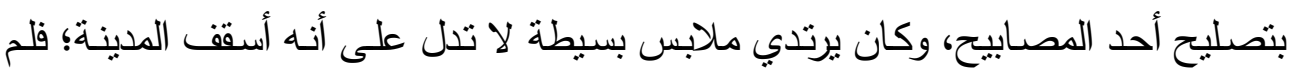

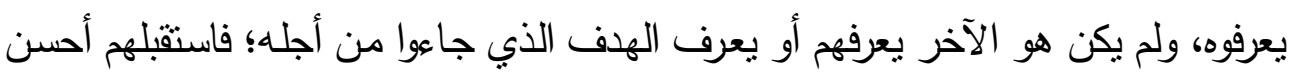

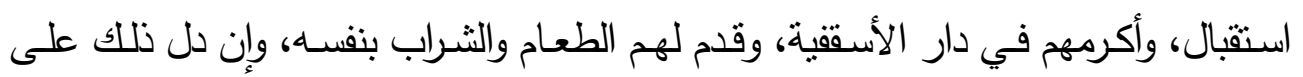

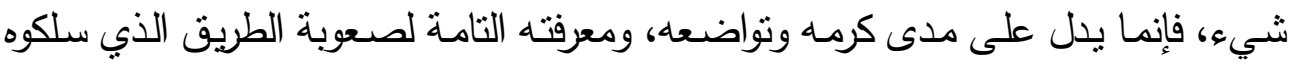

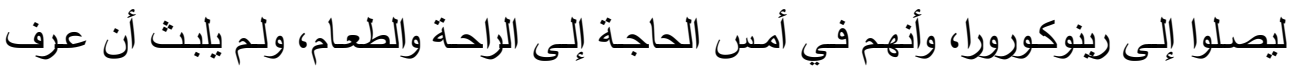

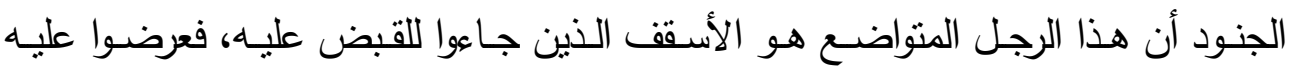

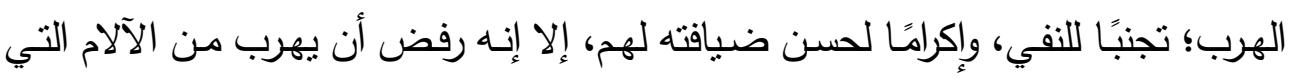

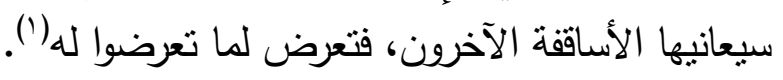

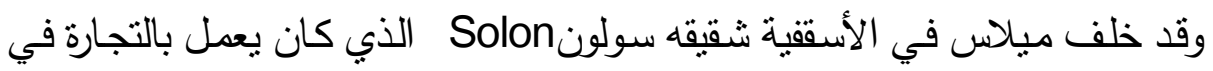

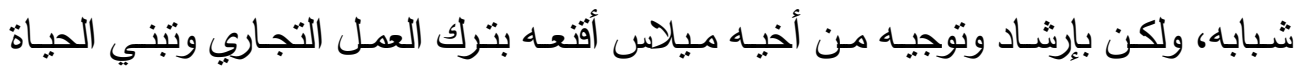

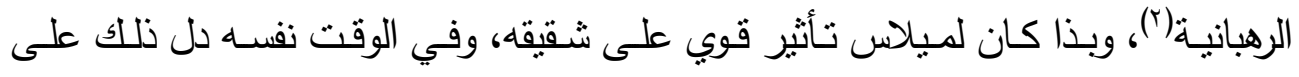

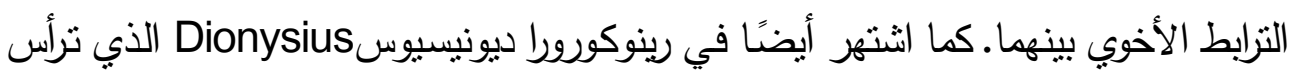

(1) Sozomen, Ecclesiastical, pp.296-7.

Cf. also, Herbert Verreth, Northern Sinai,p.288-90; lina Eckenstein , A history, p. 100.

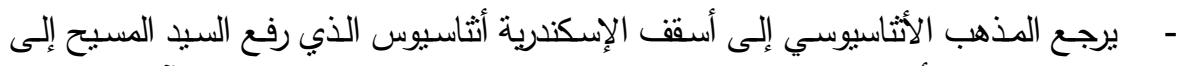

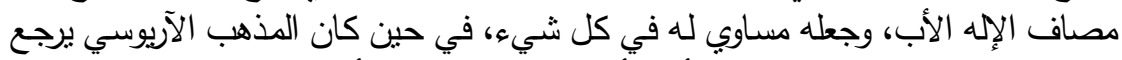

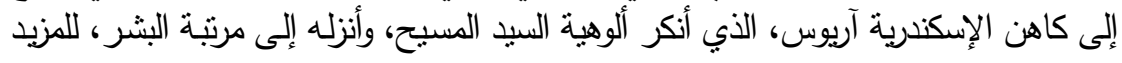

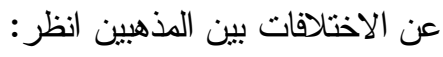

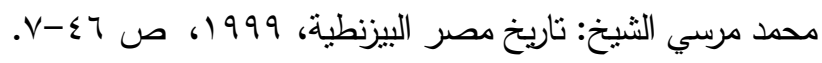

(2) Sozomenus, Church History , p. 369; Sozomen, Ecclesiastical, pp. 296 -97 . 
دير المينة الذي يقع شمال رينوكورورا، وذللك في بدايات القرن الرابع الميلادي، وقد ذكره

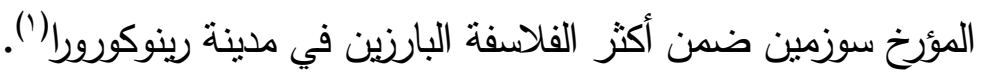

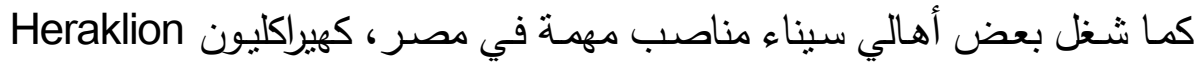

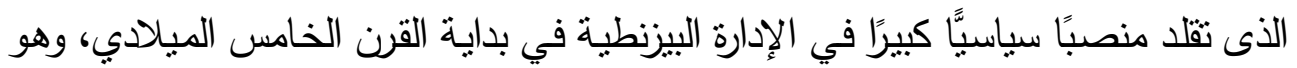

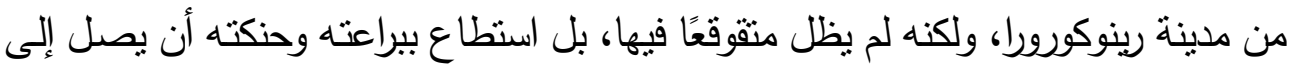

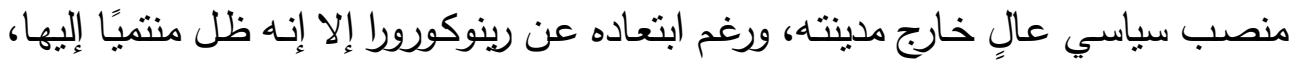

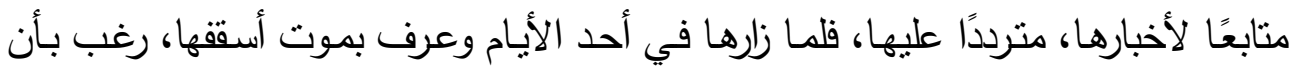

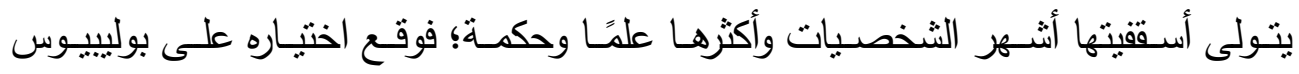

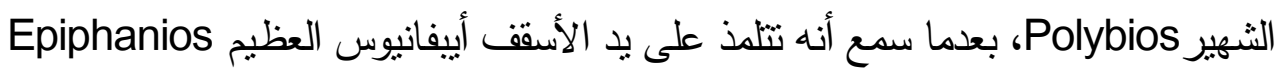

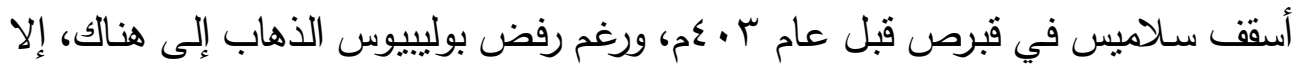

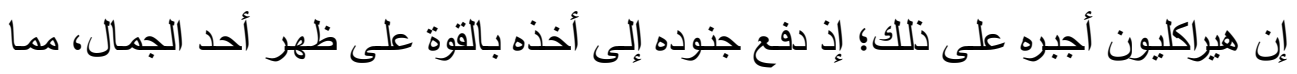
دفع بوليييوس إلى الرضوخ في النهاية لأوامر هيراكليون (؟).

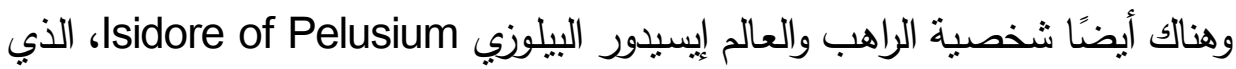

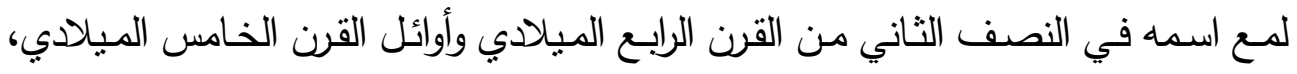

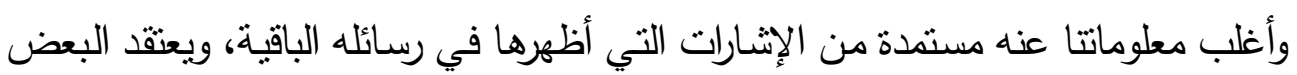

(1) Sozomenus, Church History , p. 369; Sozomen, Ecclesiastical, pp. 296.

(2) Polybii Episcopi Rhinocorurorum, Vita Sancti Epiphanii, ed, Migne, in P.L.,vol. 41,1863,(cols. 37-114),col.112.

Cf. also ,Herbert Verreth, Northern Sinai, vol.1, pp. 293-4.

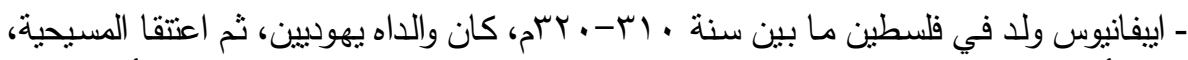

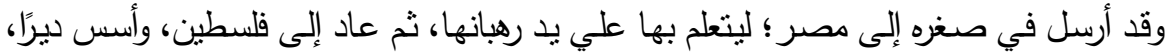

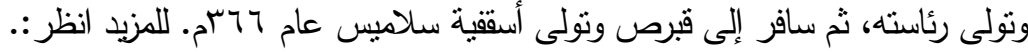
Epiphanius of Salamis, The Panarion of Epiphanius of Salamis Book I (Sects 1-46), trans . F. Williams, $2^{\text {nd }}$, Brill, Leiden, 2009, PP. XIV-XV. 


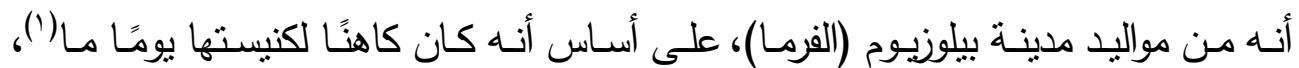

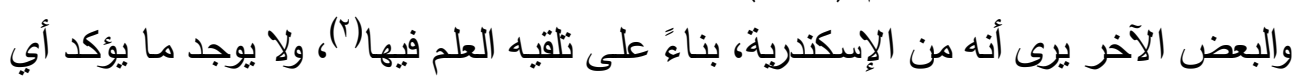

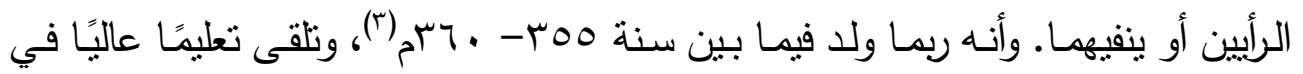

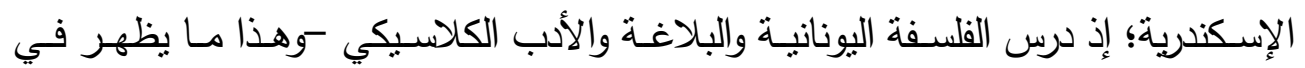

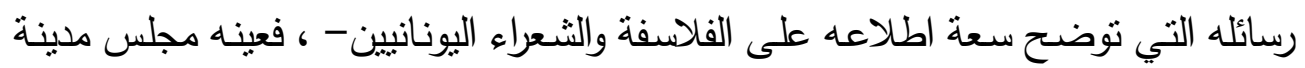

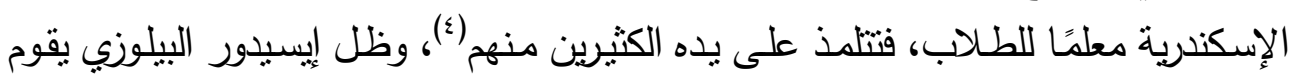

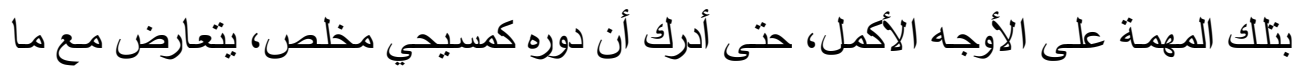

(1) Lillian Larsen,"The Letter Collection of Isidore of Pelusium", in Late Antique Letter Collections: A Critical Introduction and Reference Guide, ed. C.sogno, B.Storin \& E.Watts, University of California Press, 2017,( pp.286-308 ), p.288; Madalina Toca \& Johar Leemans, "The Authority of a 'Quasi-Bishop:Patronage and Networks in the Letters of Isidore of Pelusium", in Episcopal Networks in Late Antiquity: Connection and Communication Across Boundaries, ed. C. Cvetkovic and P. Gemeinhardt, Berlin, 2019, p.83.

( $\left.{ }^{2}\right)$ David T. Runia, Philo and the Church Fathers: A Collection of Papers, Brill,

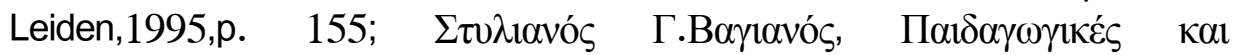

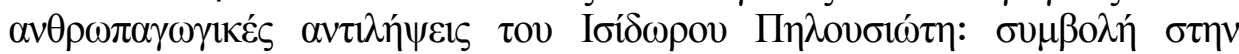

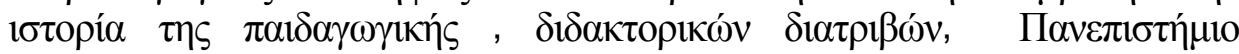

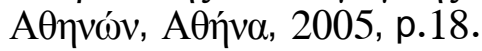

$\left({ }^{3}\right)$ Lillian Larsen, Letter Collection of Isidore, p.288 ; Madalina Toca \& Johar Leemans , Authority of a 'Quasi-Bishop, p.83.

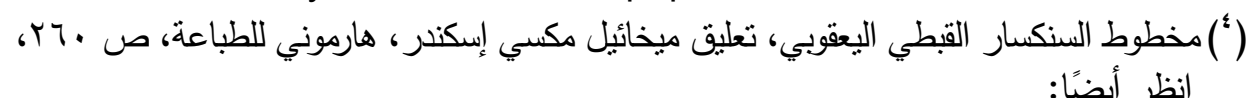

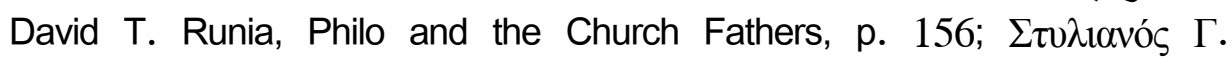

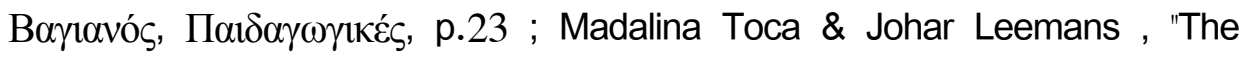
Authority of a 'Quasi-Bishop, p.83; Frank R. Trombley, Hellenic Religion and Christianization: C. 370-529, 2vols., 2nd, Brill Academic Publishers, Boston , 2001, vol.2, p.241. 


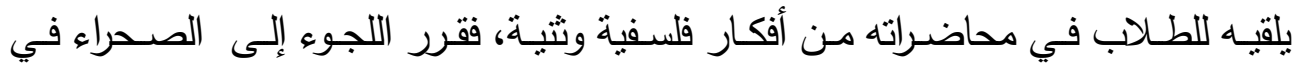

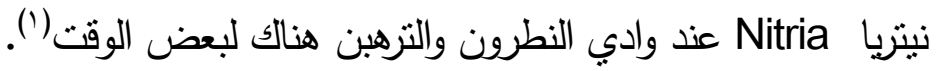

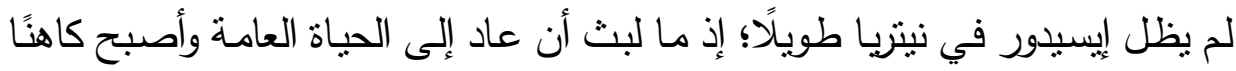

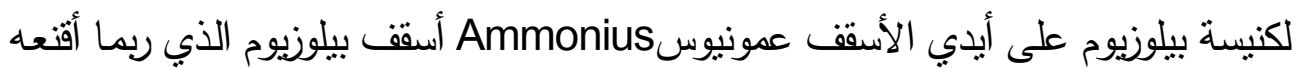

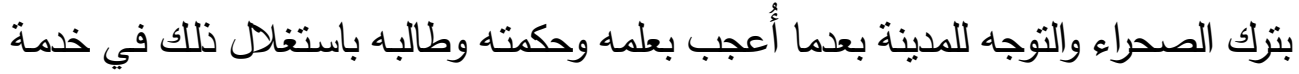

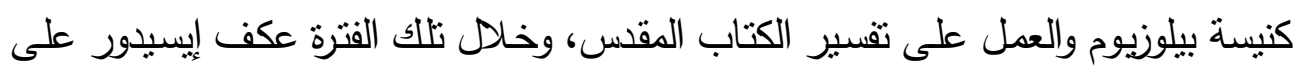

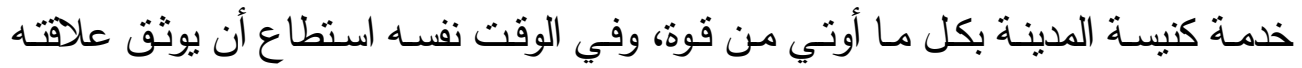

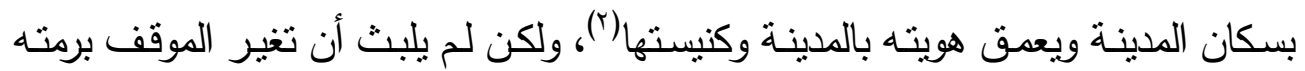

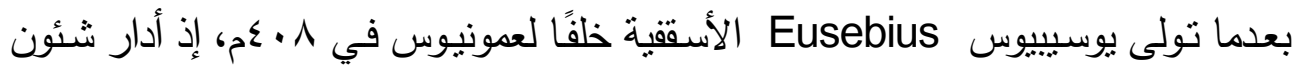

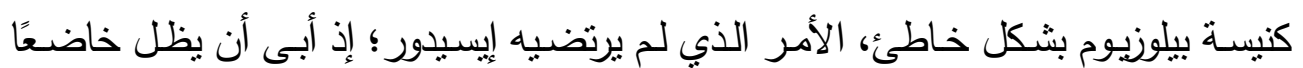

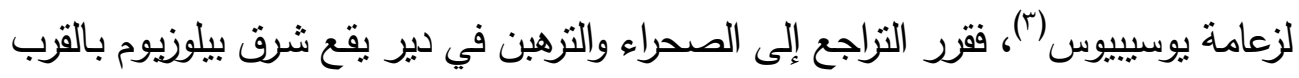

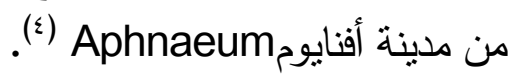
ولعل إيسيدور لم يغادر بيلوزيوم ببساطة لمجرد عدم رضائه عن أفعال أسققها، فهو

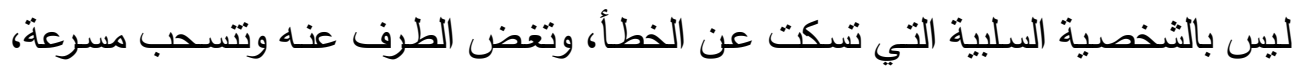

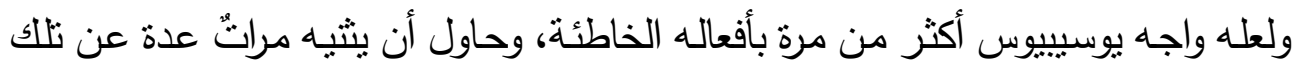

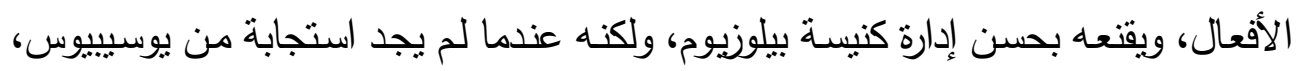

() Lillian Larsen, Letter Collection, p.288.

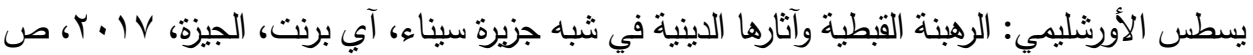

( $\left.{ }^{2}\right)$ Madalina Toca \& Johar Leemans, Authority of a 'Quasi-Bishop', p.84.

$\left({ }^{3}\right)$ Lillian Larsen, Letter Collection, p.288; Madalina Toca \& Johar Leemans, Authority of a 'Quasi-Bishop', p.84.

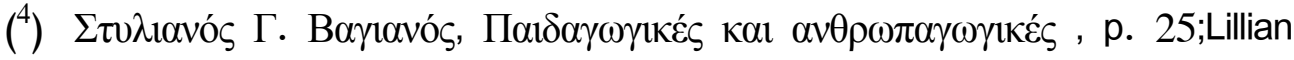
Larsen, Letter Collection, p.288.

- تقع مينة أفنايوم على ساحل البحر المتوسط، في شمال شبه جزيرة سيناء ما بين مدينتي جيرا وبيلوزيوم ،عن موقع الددينة انظر الخريطة في آخر البحث. 
فوجد حينها أن الحل الأفضل هو مغادرة الددينة وكنيستها بدلًا من أن يظل خاضعًا لزعامة

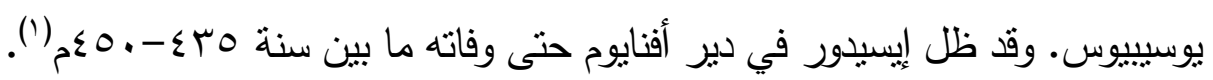

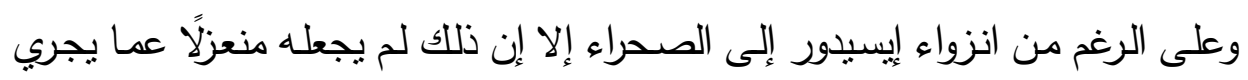

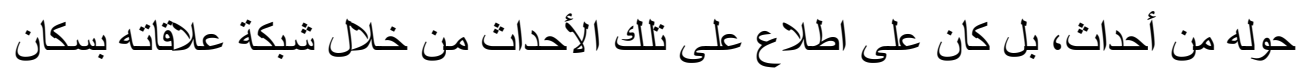

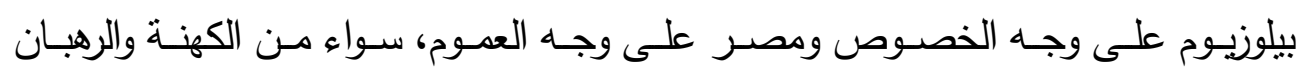

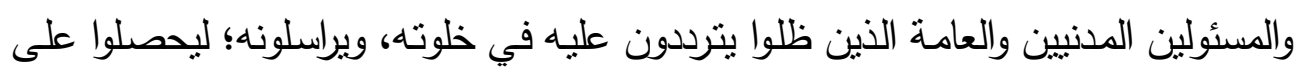
مشورته، ويشكوا إليه أوضاعهم ومشاكلهم (r). وكان إيسيبور لا يبخل على أحد من مراسليه وزائريه في الرد على استقساراتهم وتساؤلاتهم،

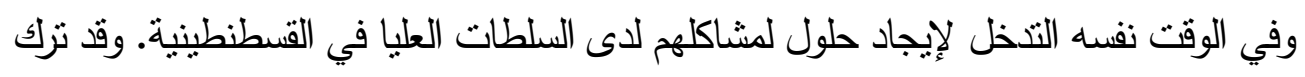

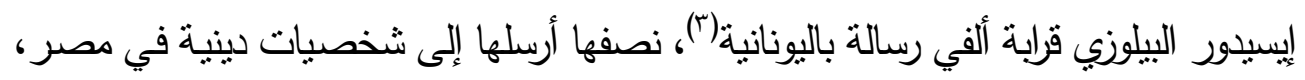

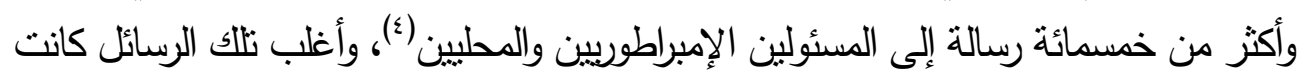

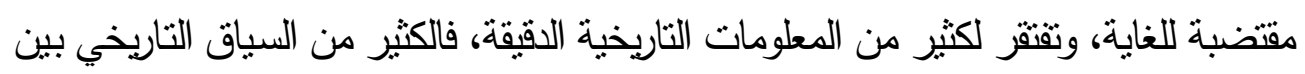

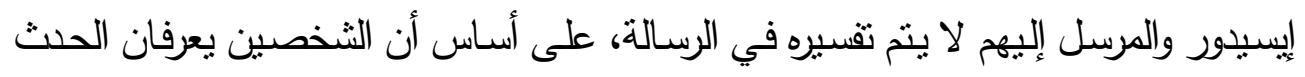

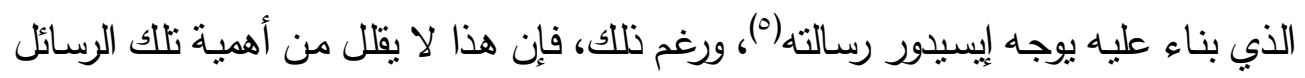

(1) David T. Runia, Philo and the Church Fathers, p.156 ; Lillian Larsen, Letter Collection of Isidore, p.288; Madalina Toca \& Johar Leemans, Authority of a 'Quasi-Bishop, p.84 .

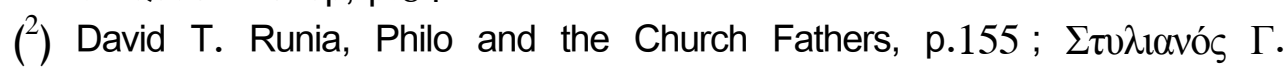

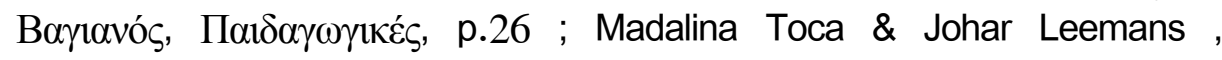
Authority of a 'Quasi-Bishop', pp.84-5 .

$\left({ }^{3}\right)$ David T. Runia, Philo and the Church Fathers, p.155 ; Madalina Toca \& Johar Leemans, Authority of a 'Quasi-Bishop, p.83.

$\left({ }^{4}\right)$ Lillian Larsen, Letter Collection of Isidore, p.290. يبطس الأورشليمي: الرهبنة القبطية، ص م. 1.

(5) Madalina Toca \& Johar Leemans, Authority of a 'Quasi-Bishop, p.85. 
التي كثفت الستار عن الدور المحوري الذي لعبه إيسيور، وقد تم جمع تلك الرسائل وحفظها من قبل تلاميذه في الدير الذي أقام فيه بقية حياته (1).

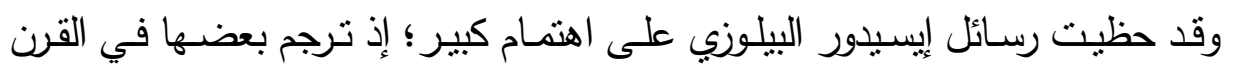

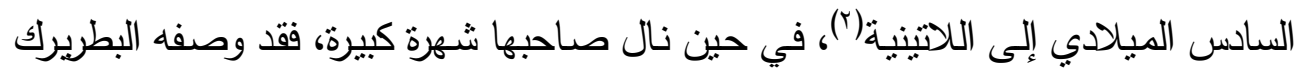

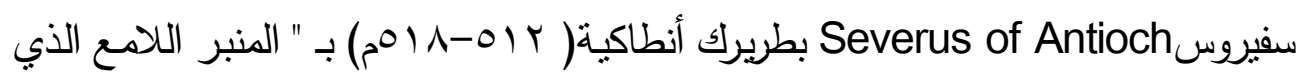

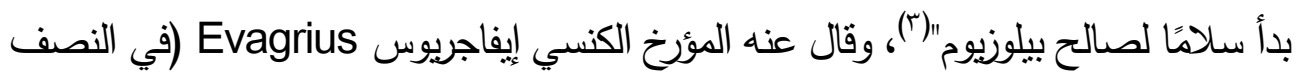

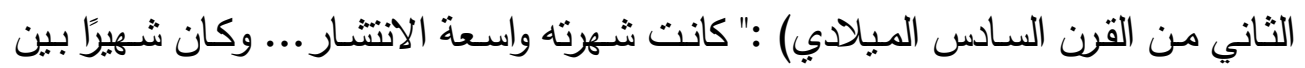

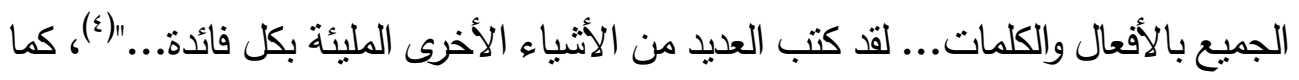

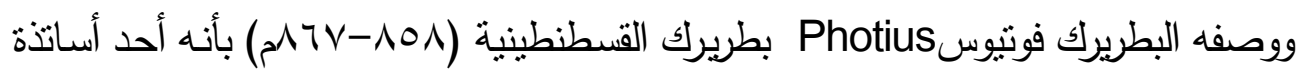

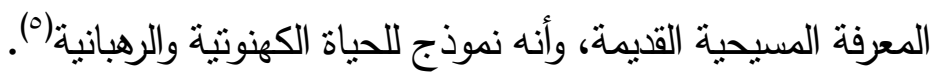

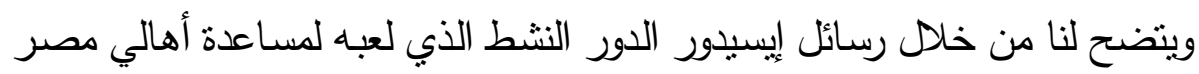

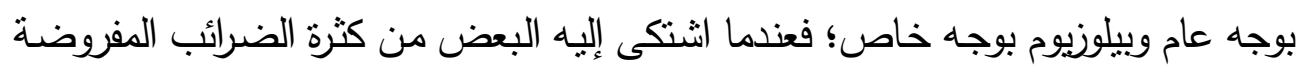

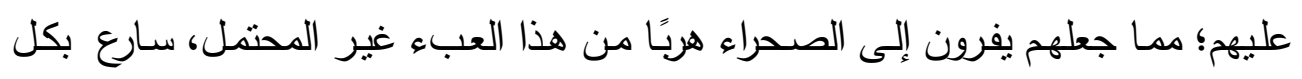

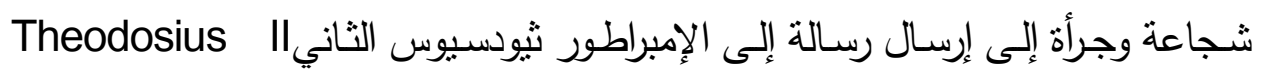

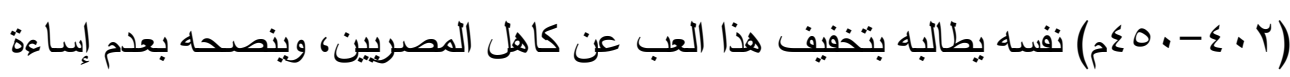

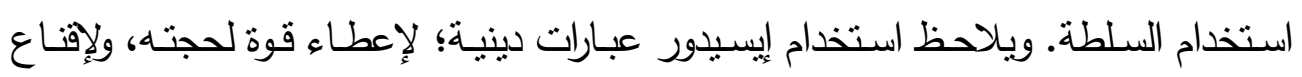

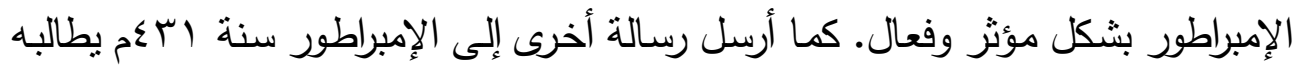

(1) Lillian Larsen, Letter Collection of Isidore, p.296.

(2) David T. Runia, Philo and the Church Fathers, p. 156.

$\left.{ }^{3}\right)$ Severus Patriarch of Antioch, The Sixth Book of the Select Letters of Severus Patriarch of Antioch in the Syriac Version of Athanasius of Nisibis, 2vols. trans. E. Brooks, Oxford, 1903, vol.2, part1, p.150.

$\left({ }^{4}\right)$ Evagrius, The Ecclesiastical History of Evagrius Scholasticus, Trans. M.Whitby, Liverpool Unviersity Press, Liverpool ,2000, p.41.

$\left({ }^{5}\right)$ David T. Runia, Philo and the Church Fathers, p. 156. 


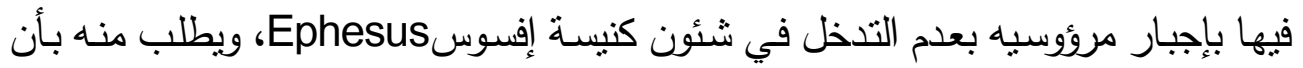

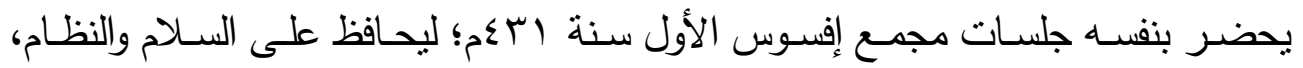

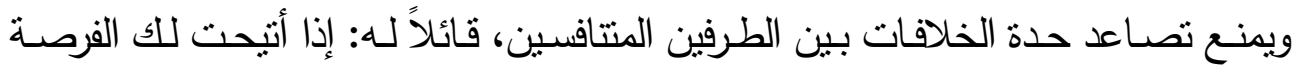

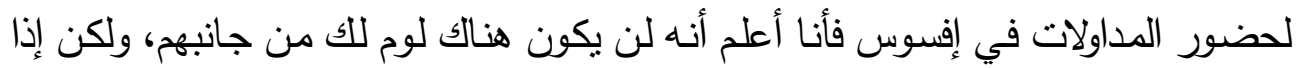
تخليت عن الحضور ... فمن سيحرر المجمع من الحماقات"(').

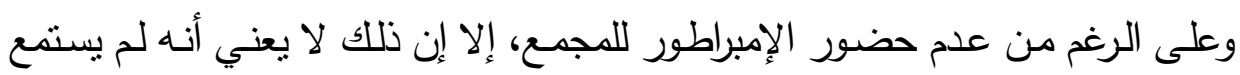

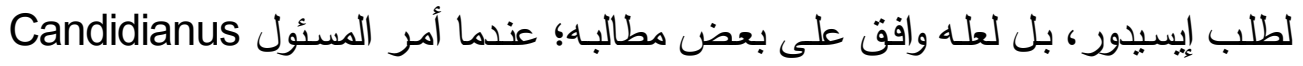
الذي أرسله لحضور المجمع بعدم التدخل في المناقتشات والاكتثاء بحفظ النظام والسـلام

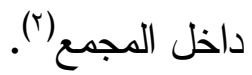

وتأتي مخاطبة إيسيدور للإمبراطور ثيودسيوس الثاني مباثرة لليليل على الدكانة الدينية

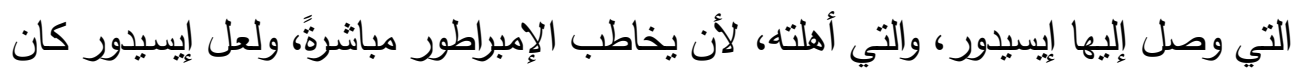

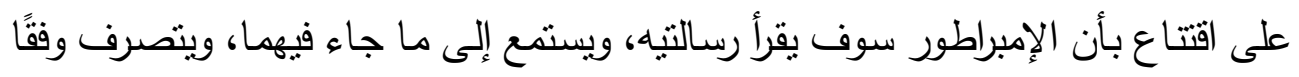

(1) Isidori Pelusiotae, Sancti Isidori Pelusiotae de interpretatione divina Scriptura. Epistolarum, ed. Auctior et Emendatior, Venetiis ,1745, Ep. 35,p.7, Ep.311, p.56 .

Cf. also, Pierre Évieux, Isidore de Péluse, Beauchesne, Paris, 1995, p.47; Nicolas Laos, The Metaphysics of World Order: A Synthesis of Philosophy, Theology, and Politics, Pickwick Publications, Eugene, 2015, pp.201-02; Madalina Toca \& Johar Leemans, Authority of a 'Quasi-Bishop, pp.91-2. مجمع إفسوس الأول : أمر الإمبراطور فيوسيوس الثاني بعقده سنة الباءم ؛ لمناقتشة آراء نسطور

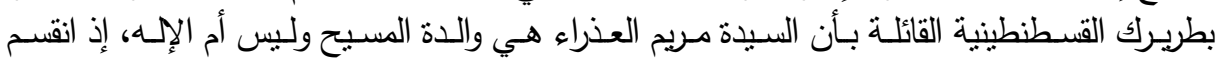

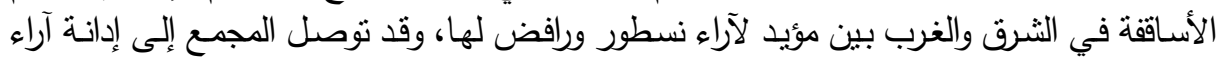

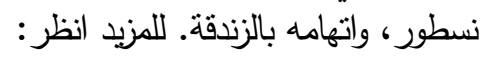

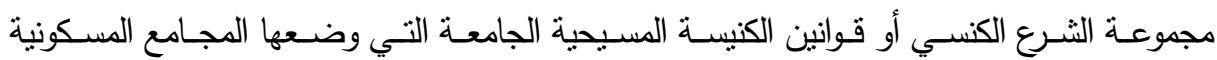

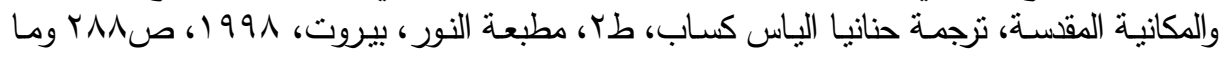

$\left(^{2}\right)$ Pierre Évieux, Isidore de Péluse, p.47. 
لهما على أقصى تقلير، أو إنه إن لم يلبِّ ما جاء بهها، فعلى الأقل يكون إيسيدور قد أدى دوره في عدم السكوت عما براه خطاً.

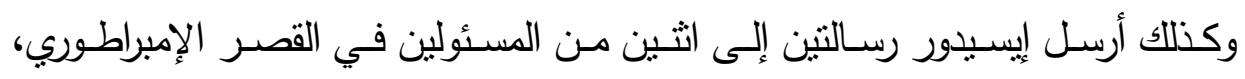

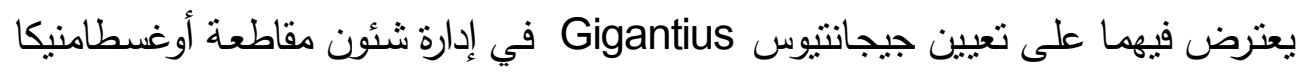

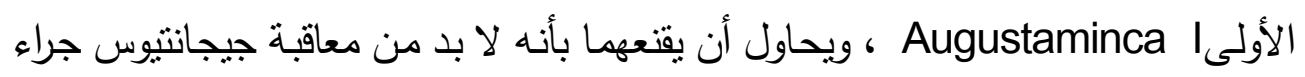

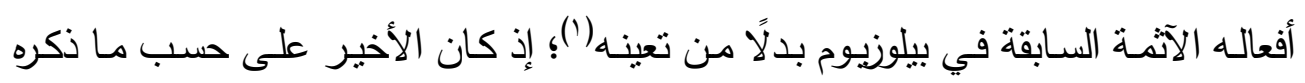

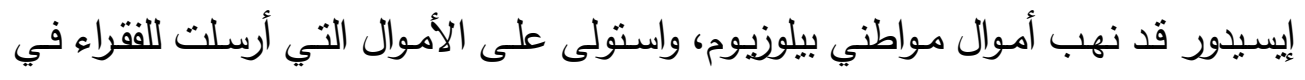

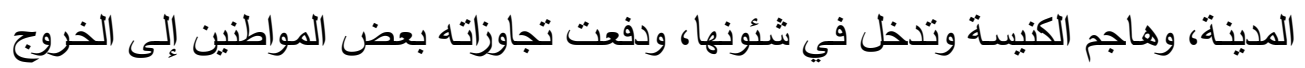

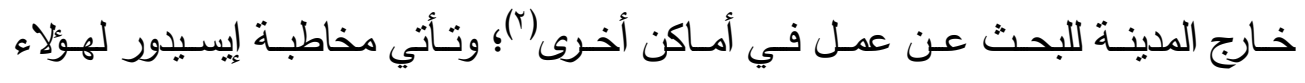

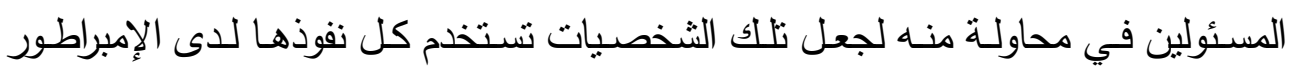

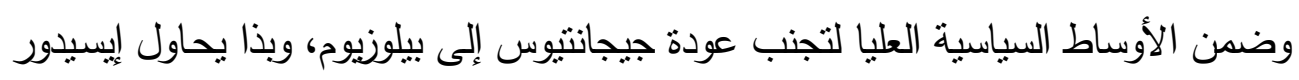

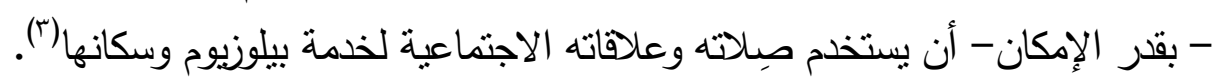

(1) Isidori Pelusiotae, Epistolarum, Ep.484,486, p.83 .

Cf. also, Pierre Évieux, Isidore de Péluse, pp.51,95.

- جيجانتيوس هو من مواليد كابدوكيا:Cappadocia ، ونولى لبعض الوقت إدارة شئون مدينة بيلوزيوم،

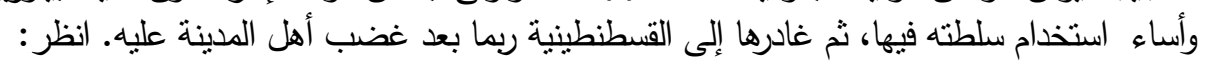
Madalina Toca,"Isidore of Pelusium's Letters to Didymus the Blind", in Studia Patristica vol.XCVI Papers presented at the Seventeenth International Conference on Patristic Studies held in Oxford 2015, ed. M. Vinzent, Peeters, Leuven , 2017,( pp.325-332), p.329.

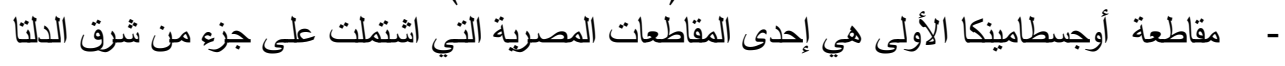

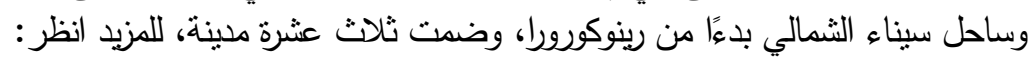

Hieroclis, Notitlae Graecae, p.47.

Cf. also, Herbert Verreth, Northern Sinai,pp.65,300.

$\left(^{2}\right)$ Isidori Pelusiotae, Epistolarum, Ep.487, p.84 .

(3) Madalina Toca \& Johar Leemans, Authority of a 'Quasi-Bishop, p.90 . 
ولم يقق دور إيبيذور على هذا فحسب، بل لعب دور الوسيط للأفراد الذين اتصلوا به،

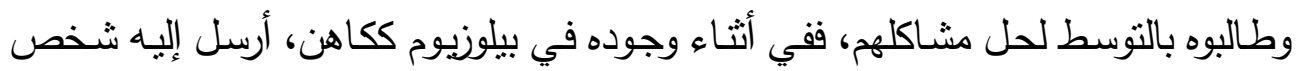

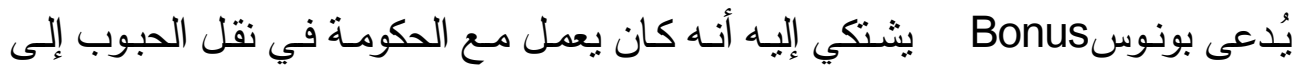

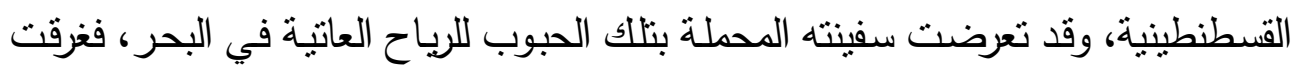

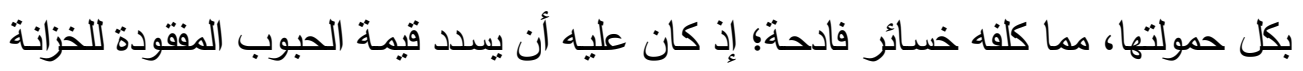
العامة، ناهيك عن خسارة سفينته، وما قد ينجم عن عدم تعاون الحكومة معه فيما بعد، مما

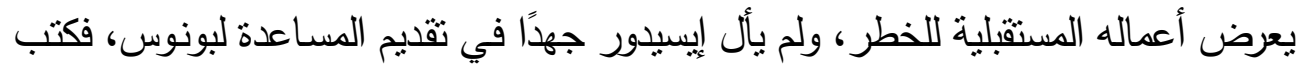

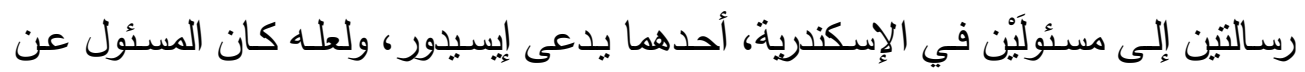

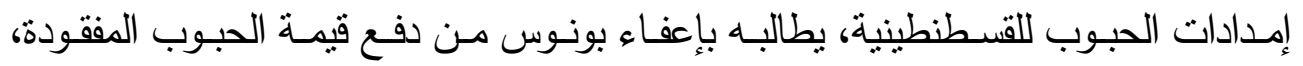

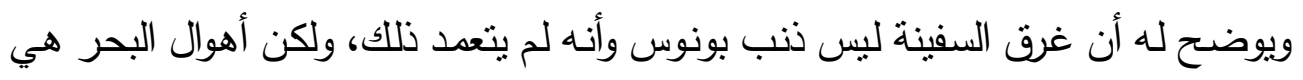

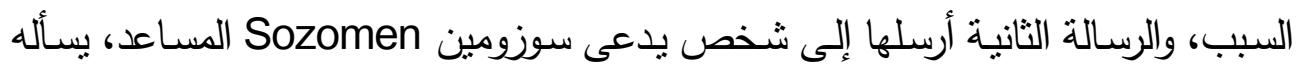

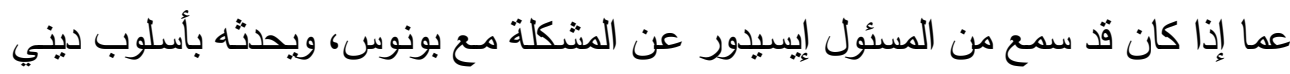

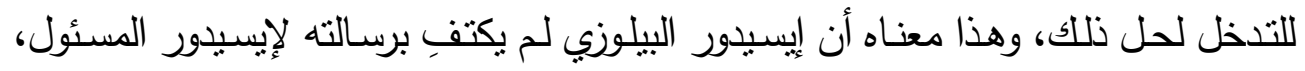

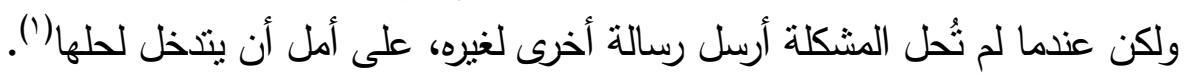

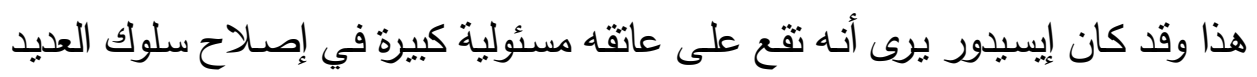

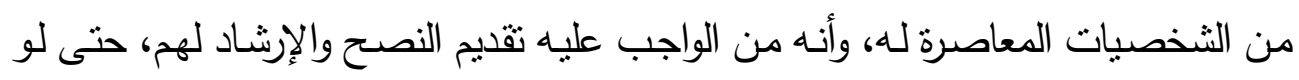

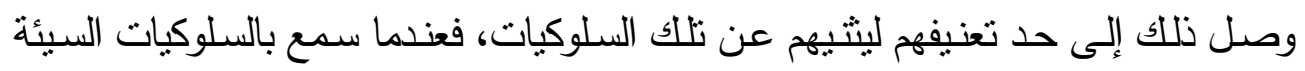

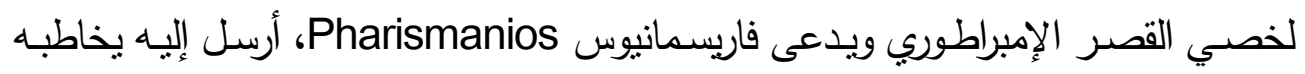

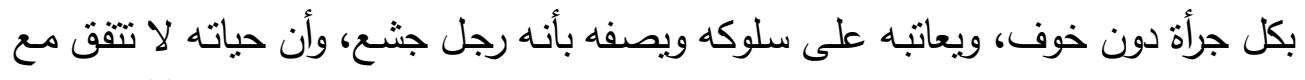

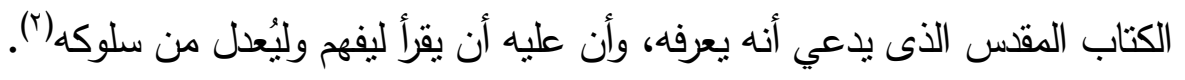

( ${ }^{1}$ Isidori Pelusiotae, Epistolarum, Eps.299,300, p.54.

Cf. also, Madalina Toca \& Johar Leemans , Authority of a 'Quasi-Bishop, p.88.

(2) Isidori Pelusiotae, Epistolarum, Ep.27, p.6 .

Cf. also, Pierre Évieux, Isidore de Pélus, p.95. 


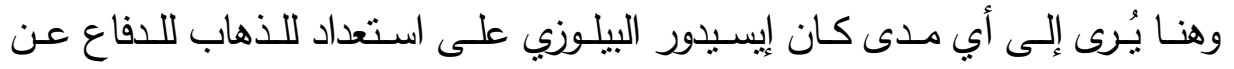

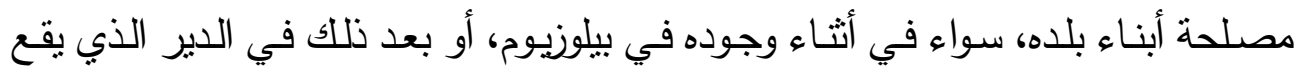

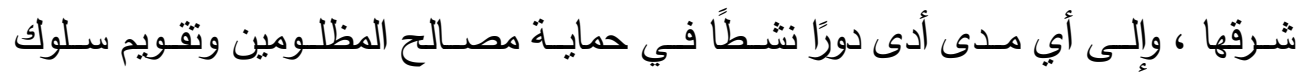

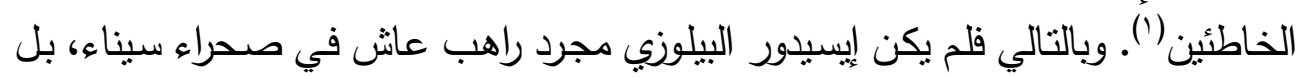

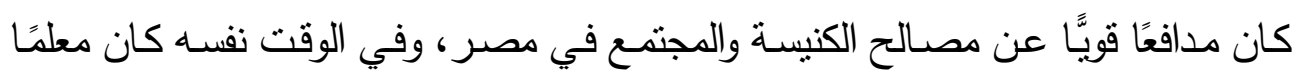

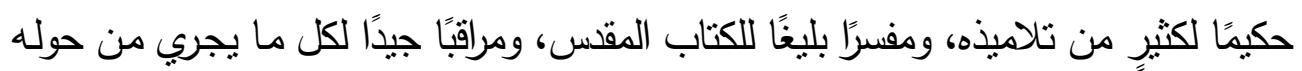

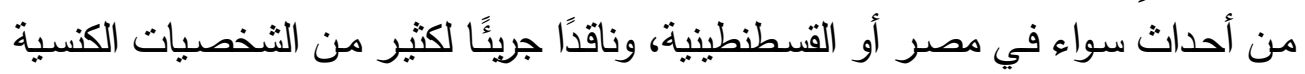

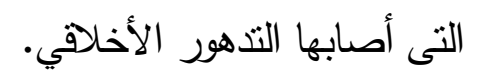
هذا عن أبرز شخصيات أهالي سيناء في العصر البيزنطي، أما في العصر الإسـامي

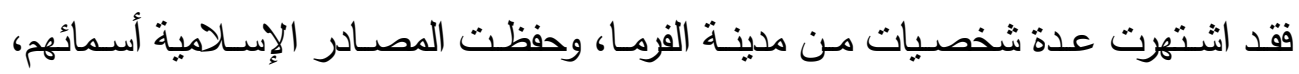

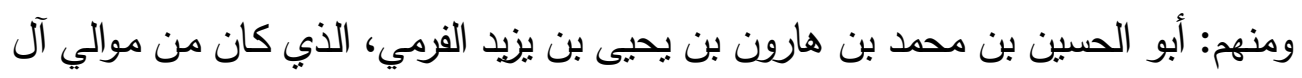

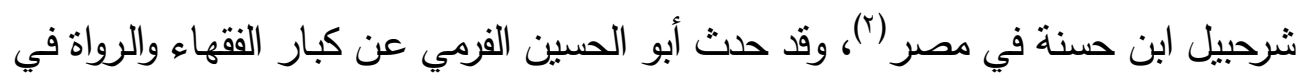

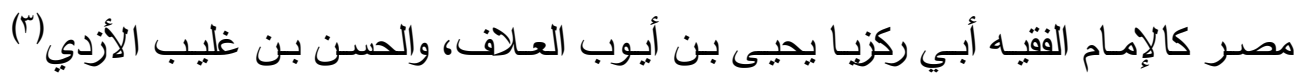

(1) Madalina Toca \& Johar Leemans, Authority of a 'Quasi-Bishop', p.90 .

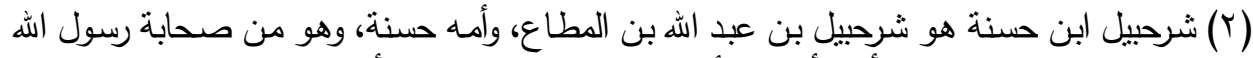

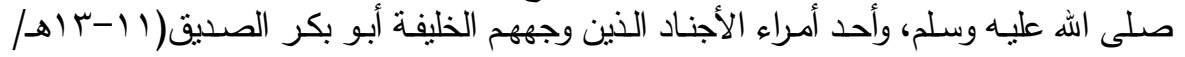

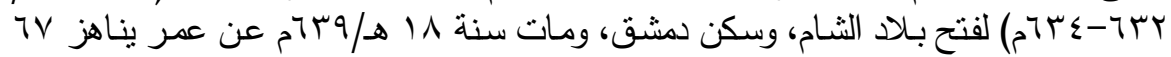

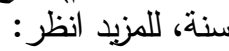
ابن عساكر : ناريخ مدينة دمشق، لآجاج، نحقيق مصطفى عبد القادر عطا، دار الكتب العلمية،

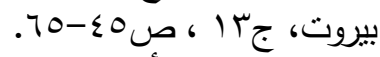

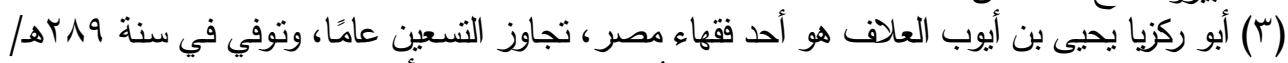

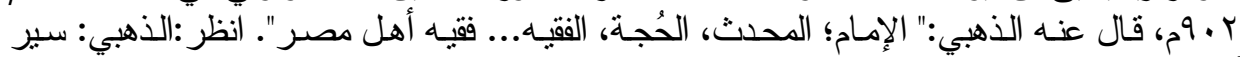

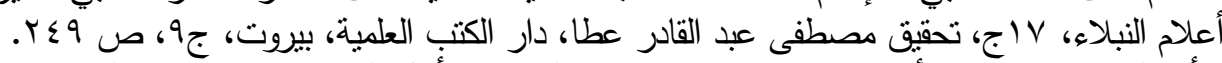

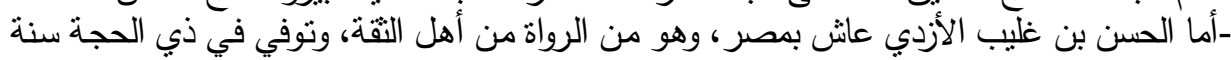

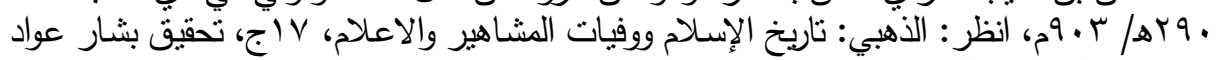

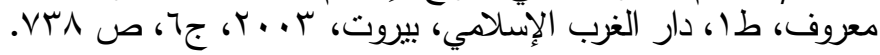


وغيرهـا، وقيل عنه إنـه: "تعم الرجل" من أهل ثقة، وتوفي في ذي القعدة سنة بـ آهـ

(') 900

ومن أهل الفرما أيضًا أبو حفص عمر بن بعقوب بن زريق الفرماوي، قيل عنه إنه

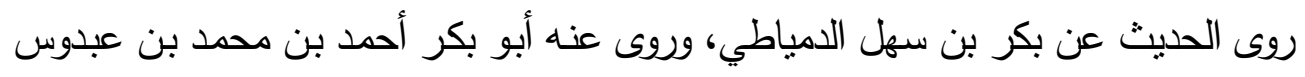

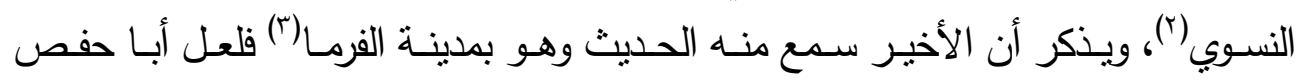

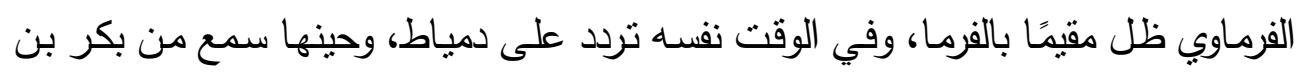

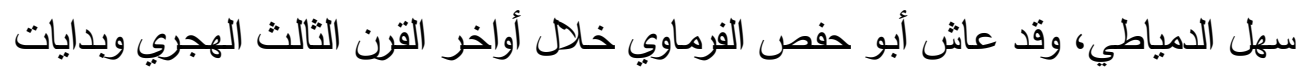

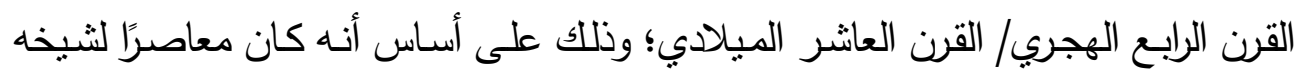

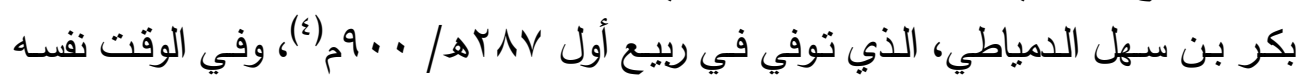

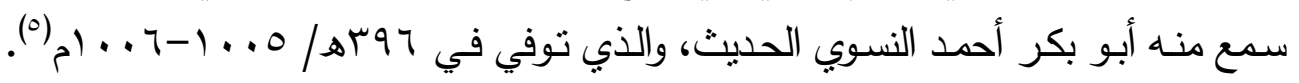

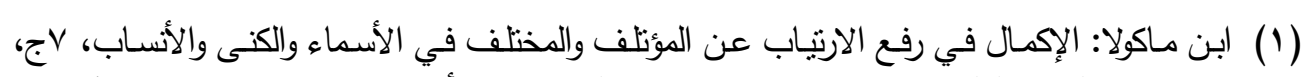

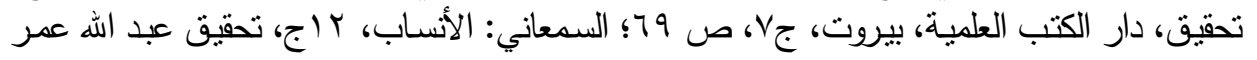

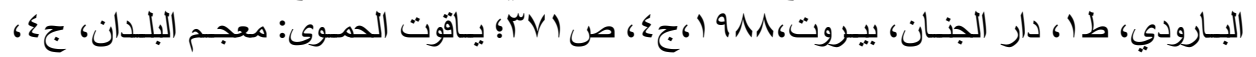

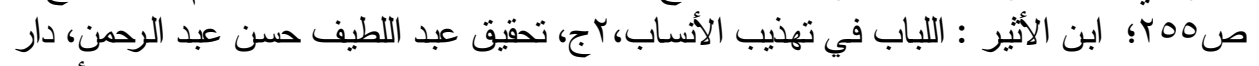

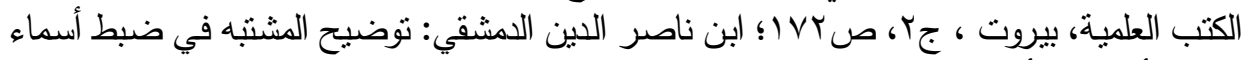

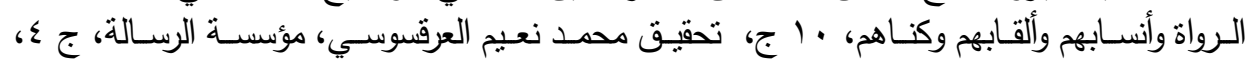

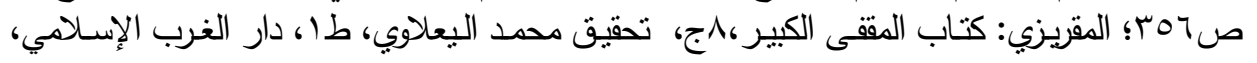

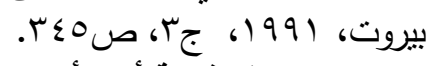
- - مانظر قائمة أبرز أعلام سيناء في العصور الوسطى في الملدق آخر البحث.

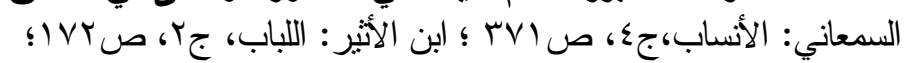

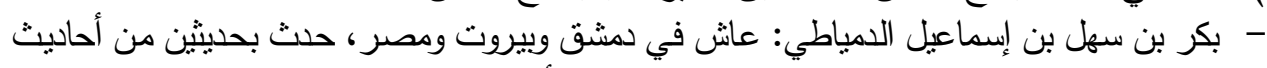

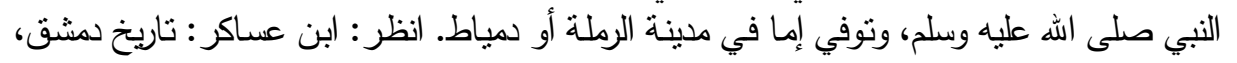

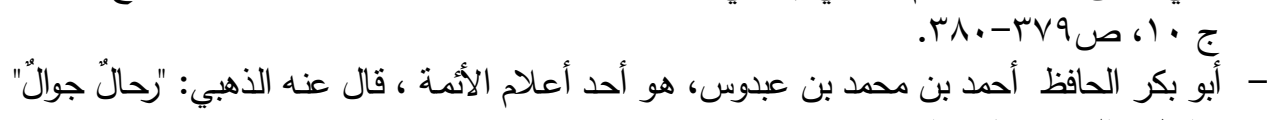

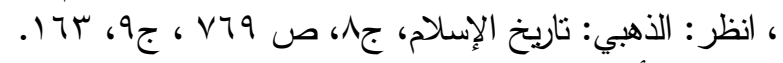

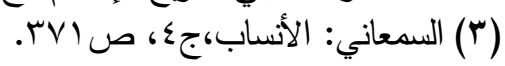

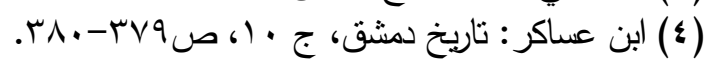

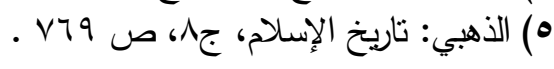




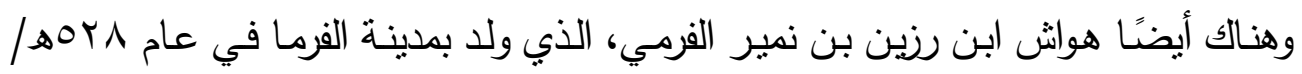

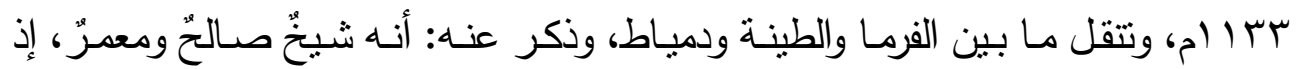

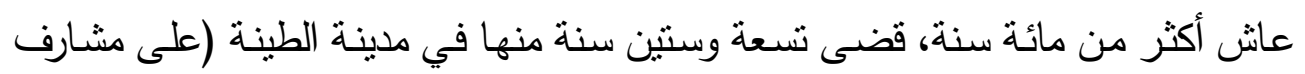

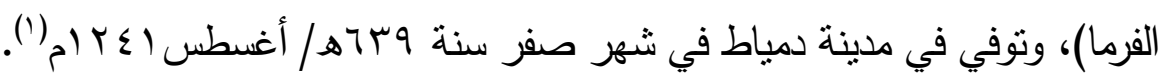

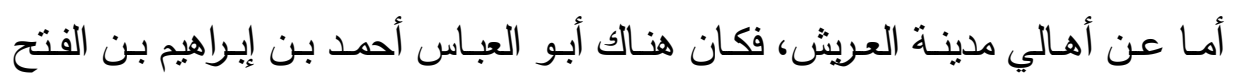

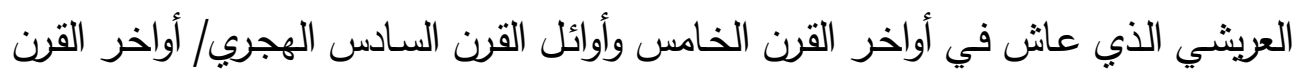

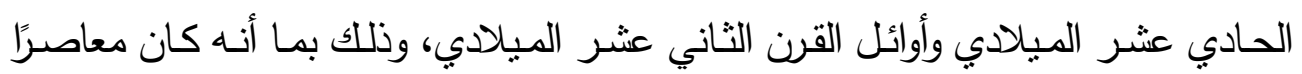

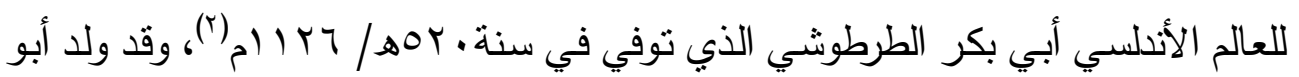

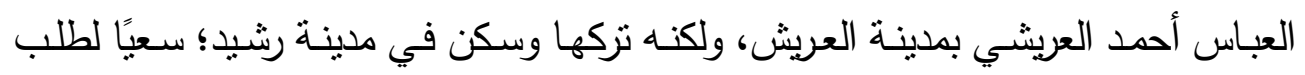

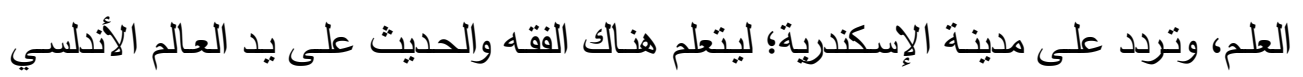

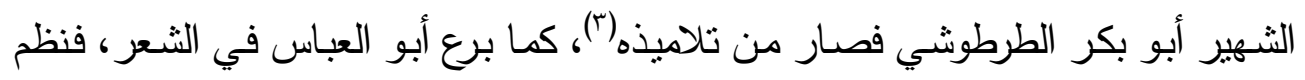

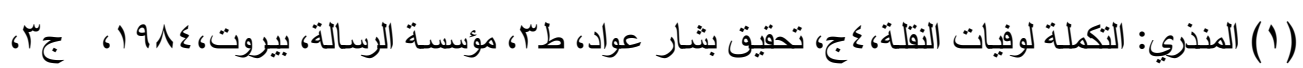

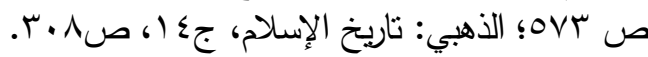

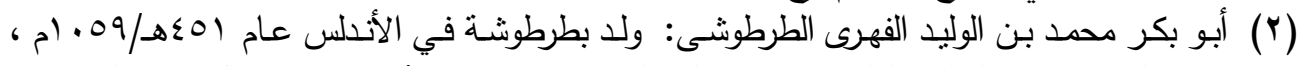

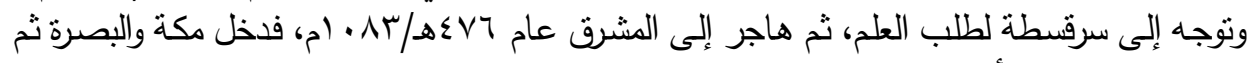

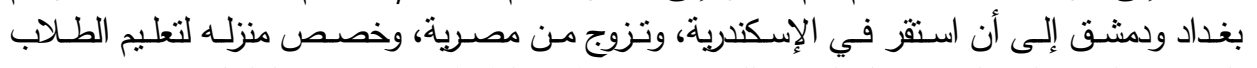

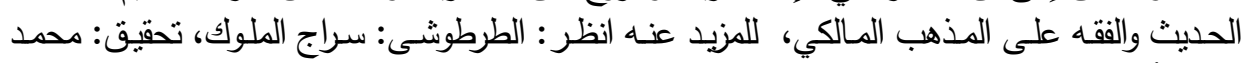

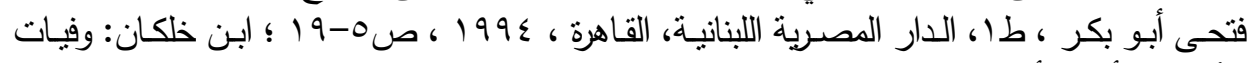

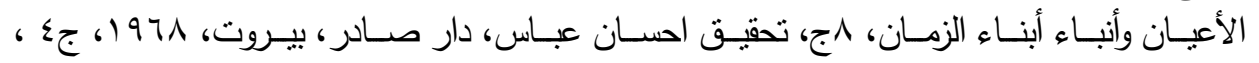
انظر أيضًا: جمال الدين الثيال :أعلام الإسكندرية فى العصر الإسلامي، مكتبـة التقافة الدينية،

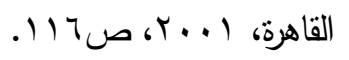

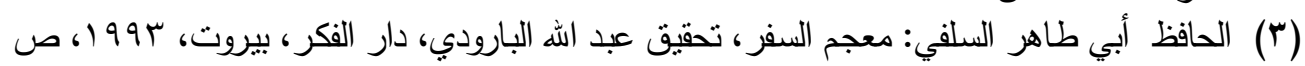

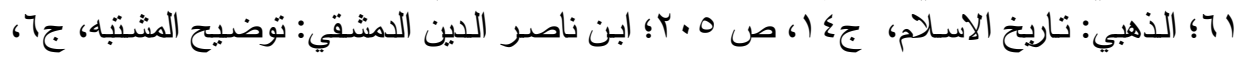


وأنثد عدة قصائد شعرية(') أورد أبو طاهر السلفي بعضها في معجمه، وقال عنه: إنه"من أهل الفقه والعفة"(r).

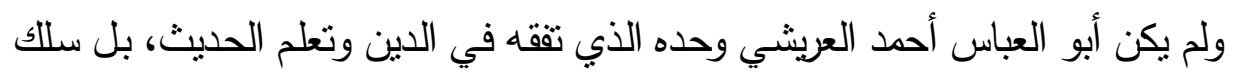

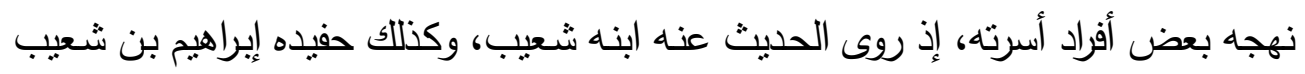

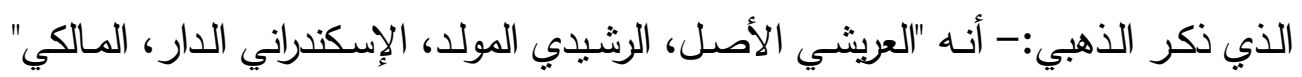

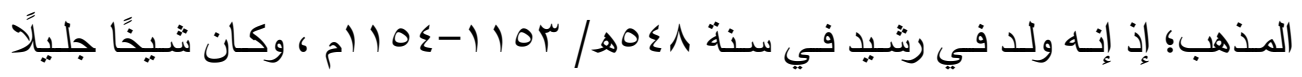

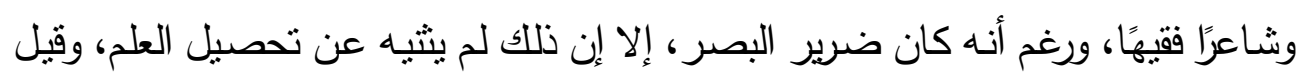

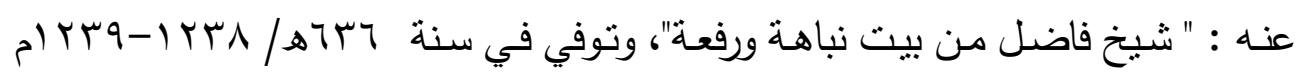

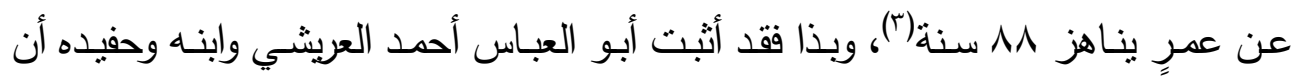

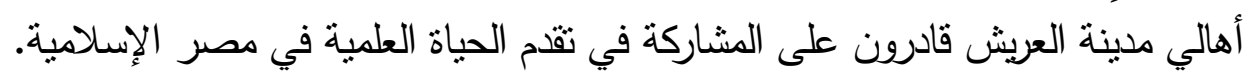

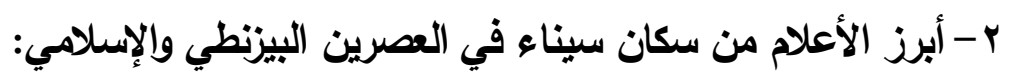

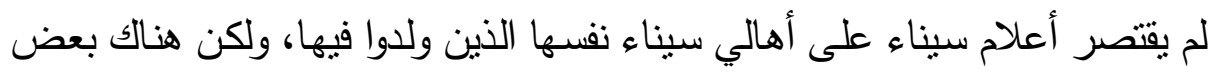

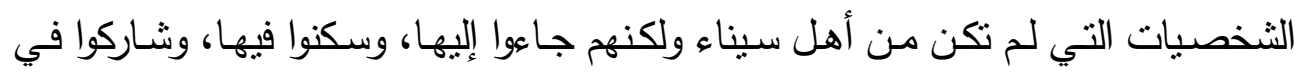

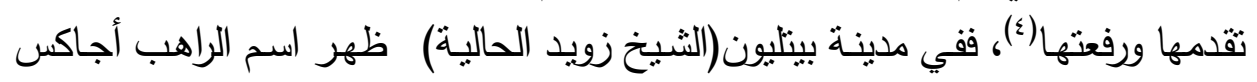

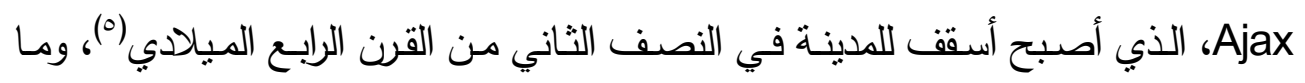

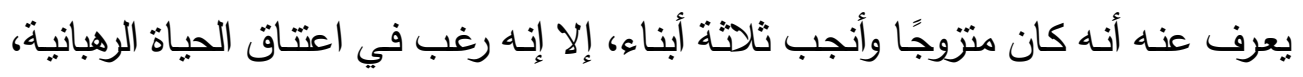

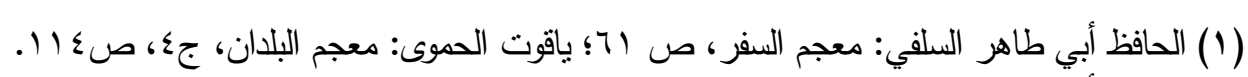

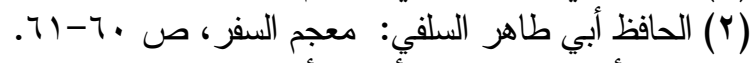

$$
\begin{aligned}
& \text { من أبيات الثعر التي أنثدها أبو العباس العريشي := } \\
& \text { وسنا الهداية من ذُجى الكفران } \\
& \text { من قوله في محكم الفرقان } \\
& \text { اللعجز والثقصير والنقصان }
\end{aligned}
$$

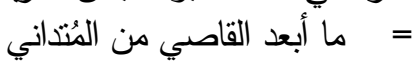

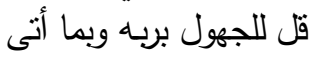

$$
\begin{aligned}
& \text { أنسبت ربك غِرة وجهالة }
\end{aligned}
$$

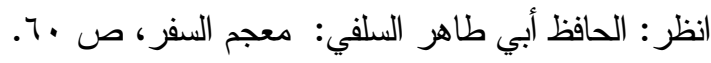

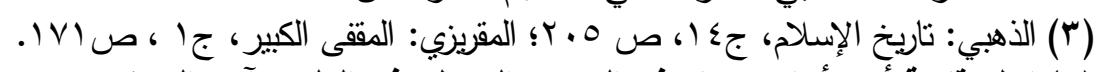

$$
\begin{aligned}
& \text { ( ) انظر قائمة أبرز أعلام سيناء في العصور الوسطى في الملحق آخر البحث. }
\end{aligned}
$$


فترك زوجته وأبناءه وترهبن في مدينة غزة، وكان شديد التمسك بدينه، فتعرض لكثير من إنها

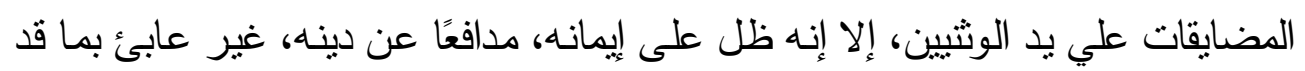

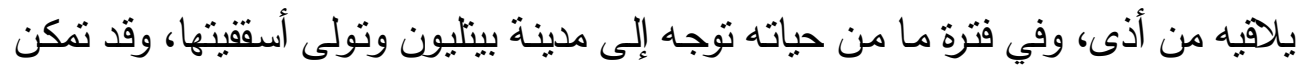

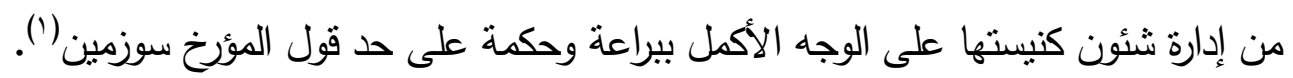

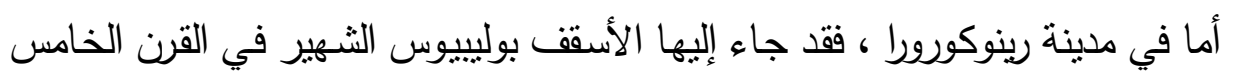

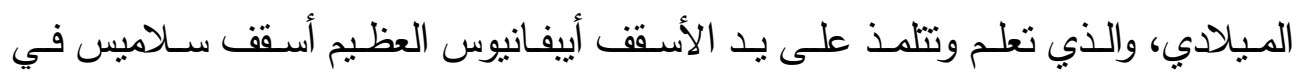

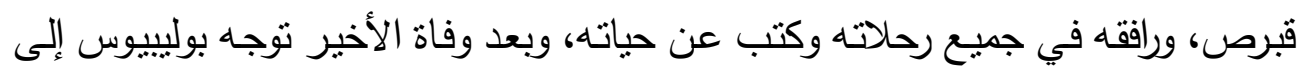

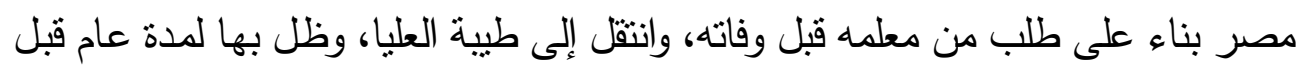

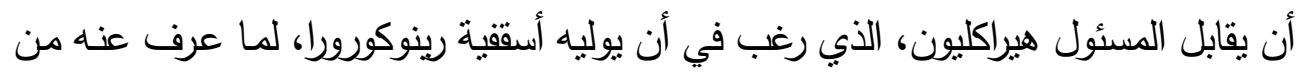

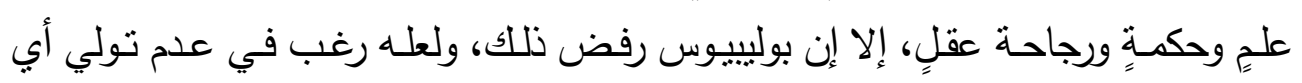

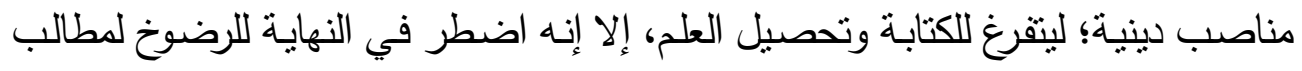

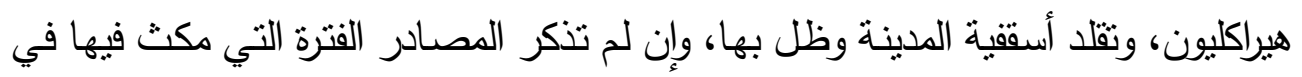

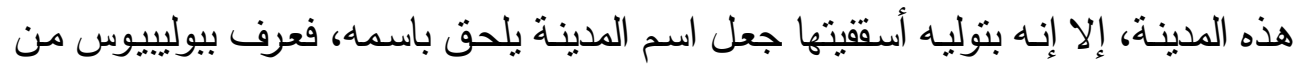
رينوكورورا، وبذا فقد جعل لهذه الددينة ذكرًا في التاريخ (r).

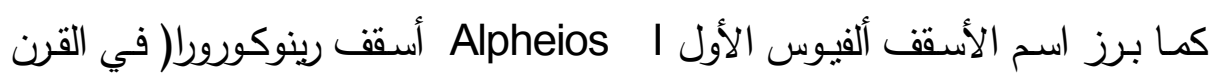

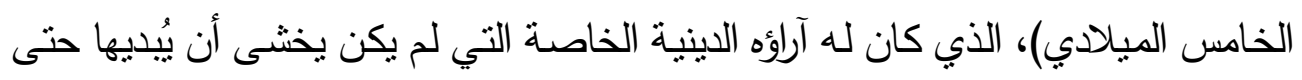

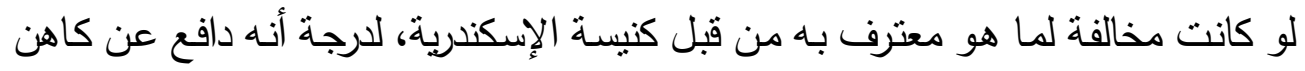

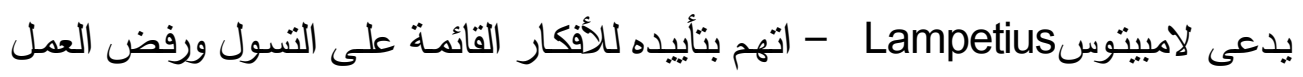

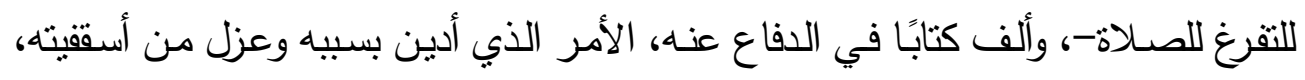

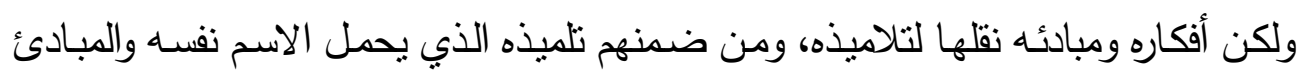

(1) Sozomen, Ecclesiastical, p.357.

(') Polybii Episcopi Rhinocorurorum, Vita Sancti Epiphanii,col.112.

Cf. also ,Herbert Verreth, Northern Sinai, pp. 293-4; lina Eckenstein, A history, p. 100. 
نفسها، والذبي لم يخشَ هو الآخر من أن يظهر مبادئـه التي اقتتع بها، فأدين من قبل

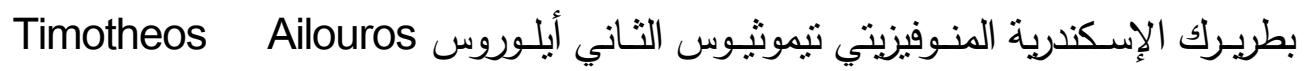
(') (م乞VV-乏०V) هذا إلى جانب مسـاهمة أحد أسـاقفة مدينة رينوكورورا في مساعدة المسيحيين الذين تعرضوا للمحن والغزوات، ألا وهو الأسقف جريجوريوس Gregorios أسقق رينة رينوكورورورا،

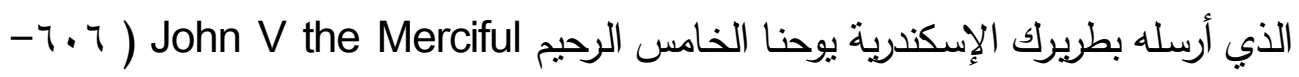

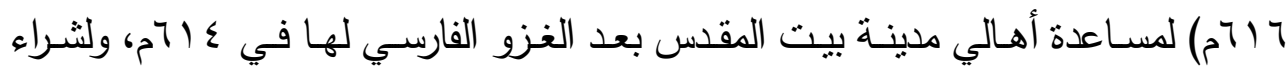

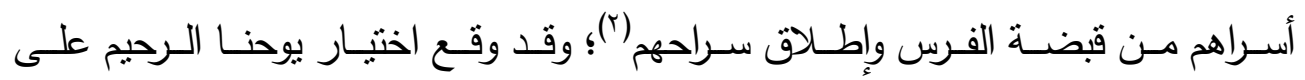

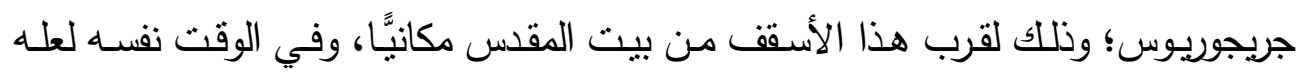

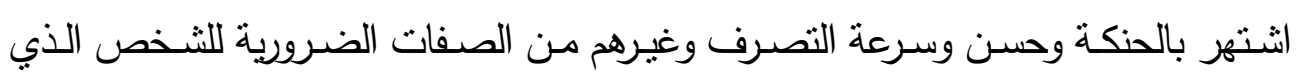
سيتعامل مع الفرس الغزاة. كما لمعت أسماء كثيرة من أساقفة شمال سيناء الذين عانشوا فيها ولعبوا دورًا بارظًا في الفي

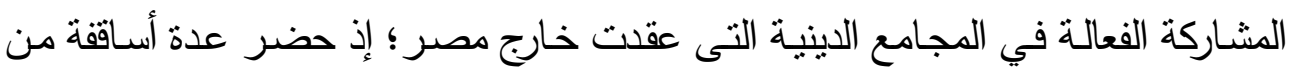

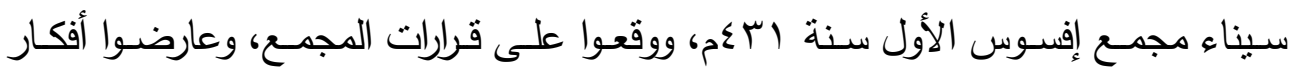

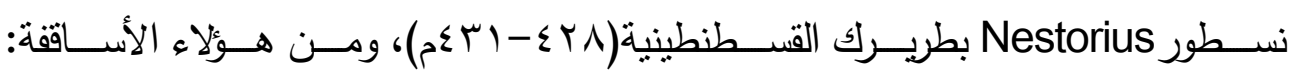

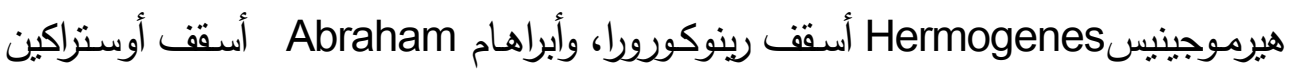

(1) Herbert Verreth, Northern Sinai, p. 298; Lina Eckenstein, A history , p.109.

(2) Sophronius, "The Life of Our Holy Father John The Father " in From Three Byzantine Saints: Contemporary Biographies of St. Daniel the Stylite, St. Theodore of Sykeon and St. John the Almsgiver, trans. Elizabeth Dawes, and introductions and notes by Norman H. Baynes, London, 1948, p.204. انظر أيضًا: محمد فرحات: "الغزو الفارسي لبيت العقس ع الآم"، في دراسات في تاريخ الدولة البيزنطية،

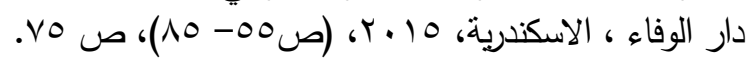


Ostrakine Hieracis

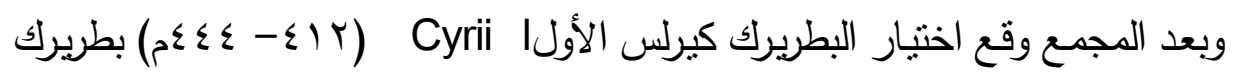

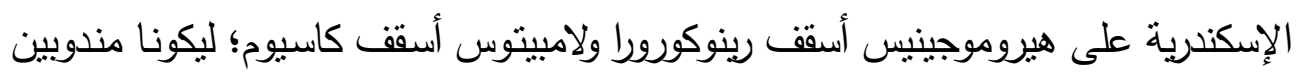

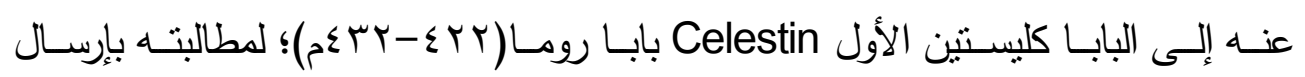

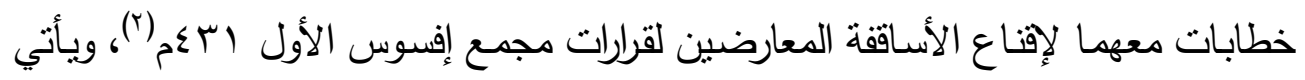
اختيار البطريرك كيرلس الأول لهاتين الثخصيتين ليكونا مندوبين عنه، ومتكلمبن باسمها؛

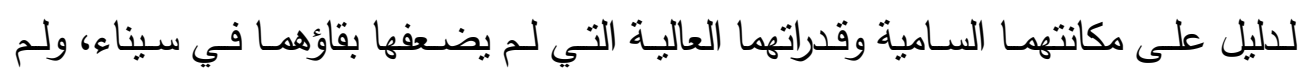
يجعهما وجودهما هناك مهشين أو منعزلين.

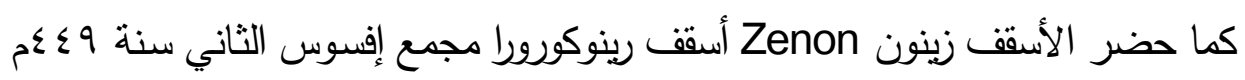

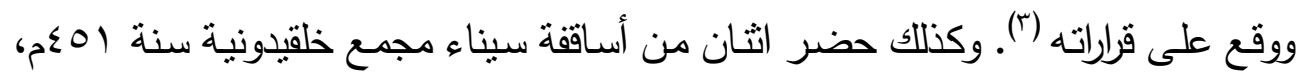

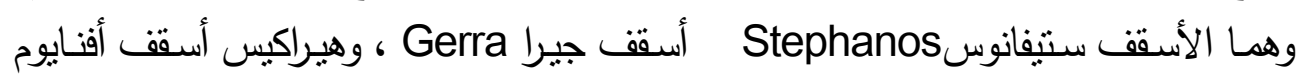
اللذان كانا ضمن الأساقفة المصريين العشرين الذين حضروا المجمع في جلسته الأولى، وهري،

(1) The Acts of the Council of Chalcedon, 3vols., Trans. Richard Price and Michael Gaddis, Liverpool University Press, Liverpool, 2005, vol.1, pp. 299, 338.

Cf. also, Herbert Verreth, Northern Sinai, p.374, p.472.

$$
\text { - عن موقع هذه العدن انظر الخريطة في آخر البحث. }
$$

(2) Pau Figueras, From Gaza to Pelusium, in Beer- Sheva, vol. 14, BenGurion University of the Negev Press, 2000, p. 140 ; lina Eckenstein, A history, p. 109.

(3) Acts of The Council of Chalcedon, vol. 1, pp.146, 291,363.

Cf. also,Herbert Verreth, Northern Sinai, p. 296.

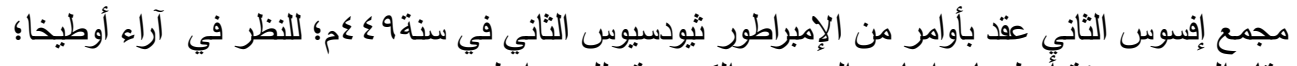

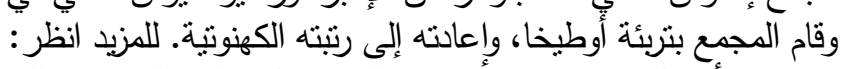

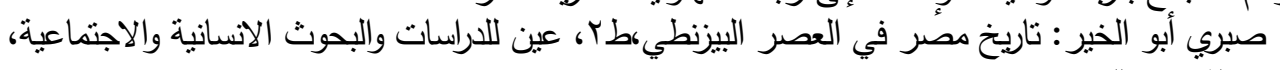

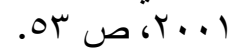




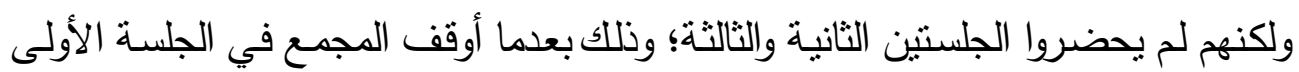
بطريرك الإنسكندرية ليوسقوروس ل Dioscorus

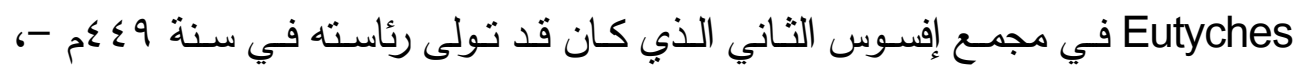

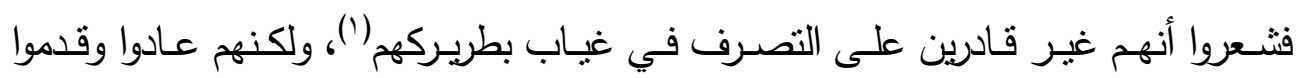

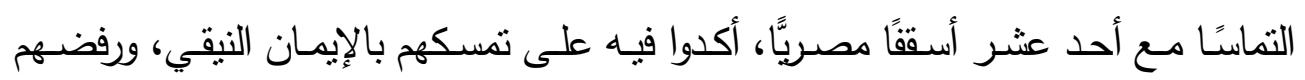

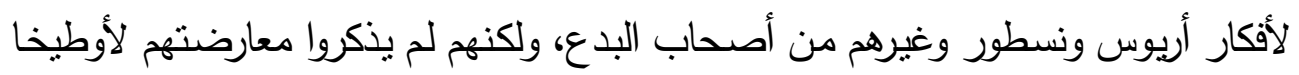

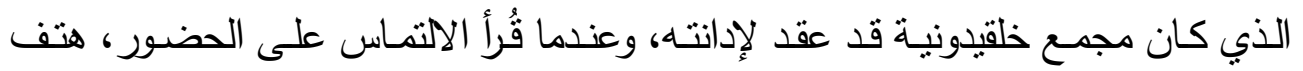

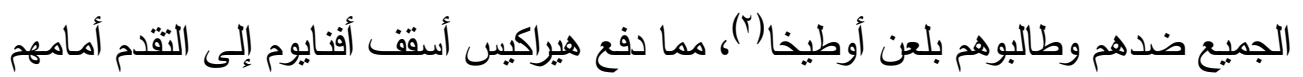

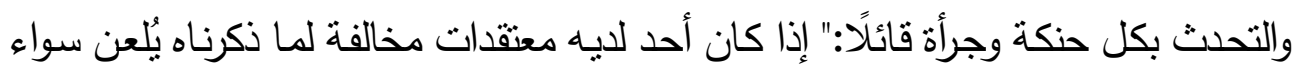

(1) Acts of The Council of Chalcedon, vol. 2,p. 148, n.34.

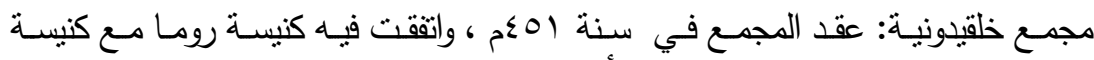

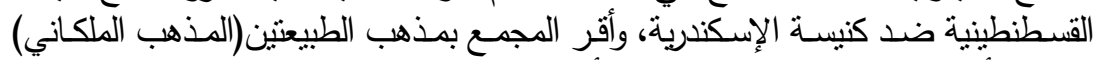

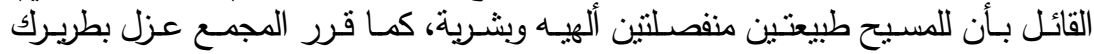

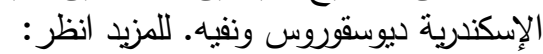

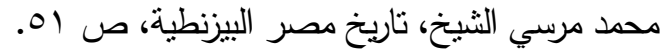

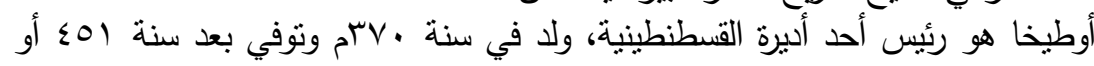

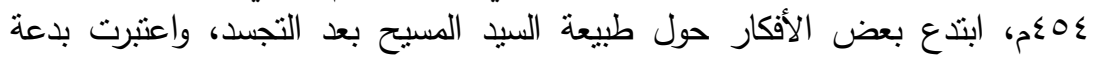

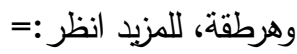

= Kazhdan and Others, O.D.B, 3 Vols , Oxford University Press, Oxford, 1991,vol.2, p. 759.

(2) Acts of The Council of Chalcedon, vol.' 2, p.148-49.

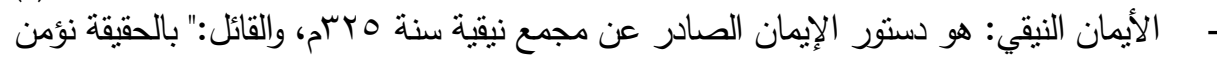

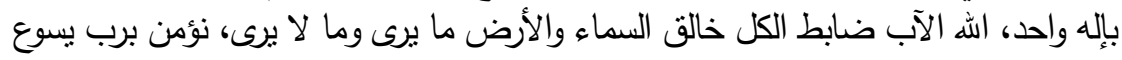

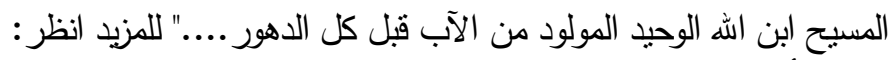

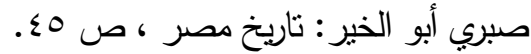


كان أوطيخا أو أي شخص آخر ... وأنتا ننظظر قرار أسققنا الأقس [بطريرك الإسكندرية] .... لأننا سنتبعه في كل شيء...." (1).

وبنلك فقد امتتع هيراكيس ومن معه من الأساقفة عن المواققة على ما جاء في الجلسة

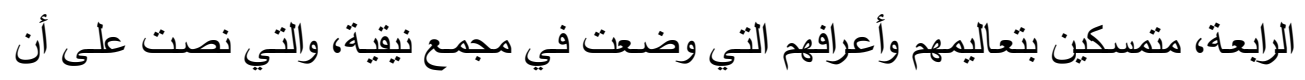

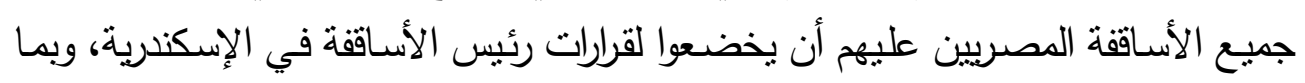

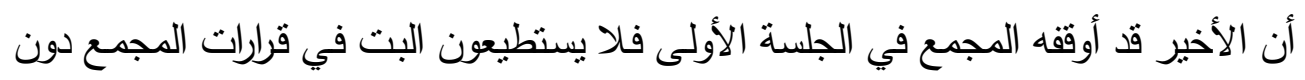

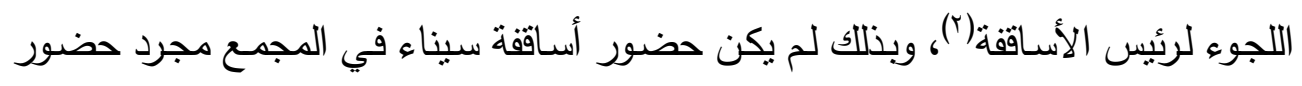

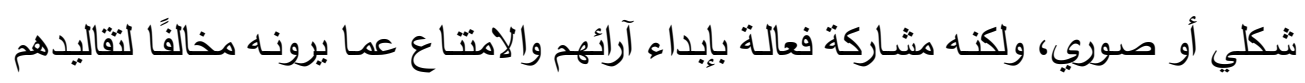
الكنسية.

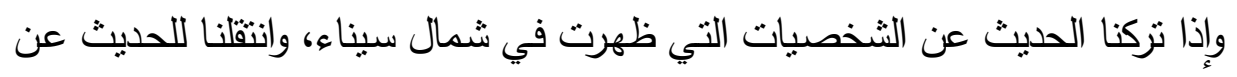

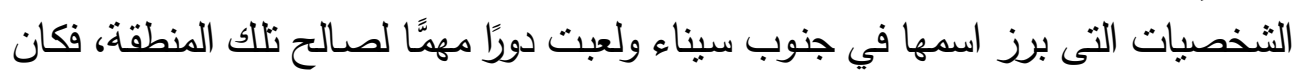
هناك جريجوري الأنطاكي Gregory of Antioch وذللك في النصف الثاني من القرن

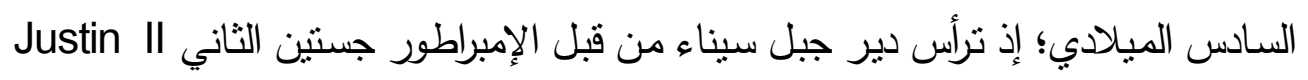

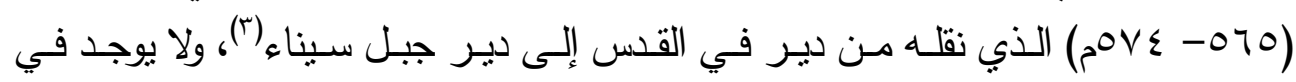

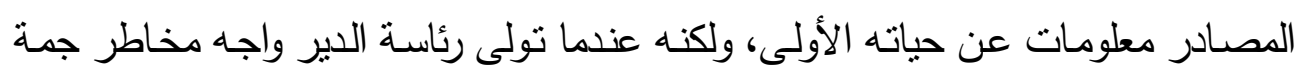

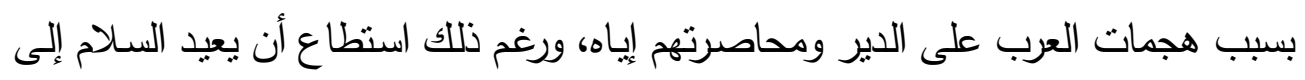

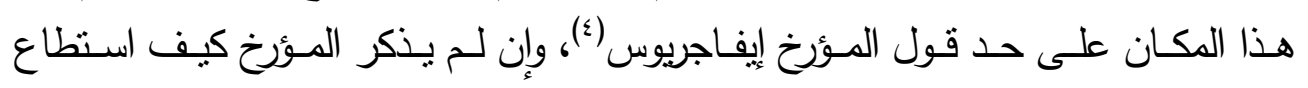

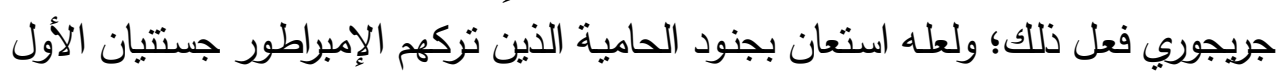
I I Justinian I

(1) Acts of The Council of Chalcedon, vol. 2, p.152.

(2) Acts of The Council of Chalcedon, vol. 2,p. 149-50.

(3) Evagrius, Ecclesiastical History, p. 262.

Cf. also, Iffan Shahid, Byzantium and the Arabs in the Sixth Century, 2vols., Dumbarton Oaks, America, 1995, vol. 1, part. 1, p.352.

$\left.{ }^{4}\right)$ Evagrius, Ecclesiastical History, p. 262. 
خطر العرب الذين كانوا يهاجمون المنطقة باستمرار (')، أو لعله عقد معهم صلحًا، معتمدًا

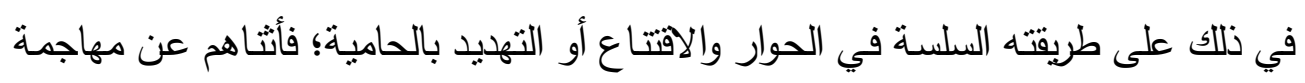

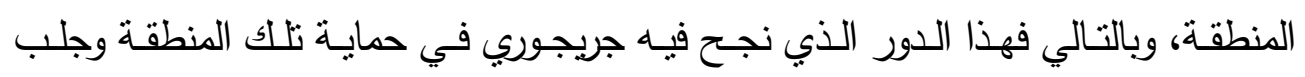

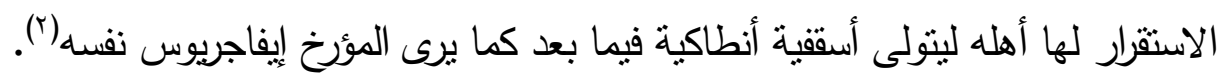

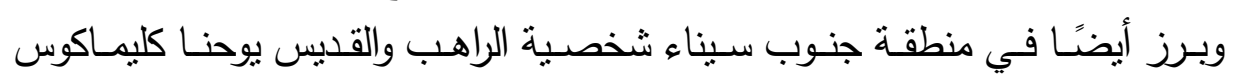

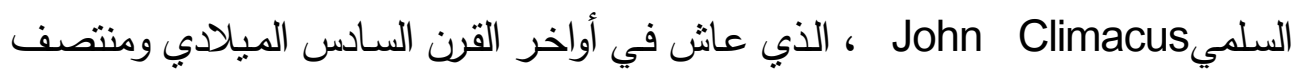

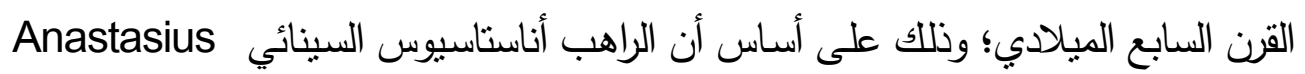

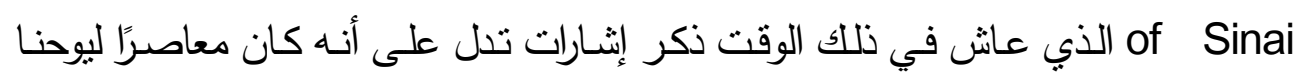

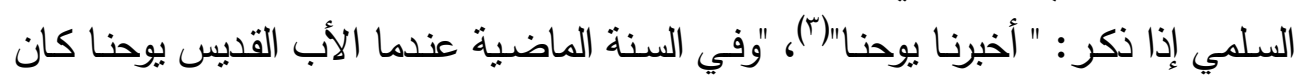

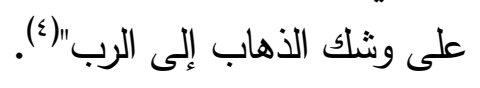

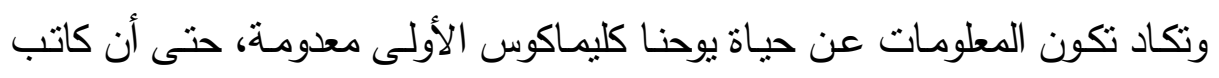

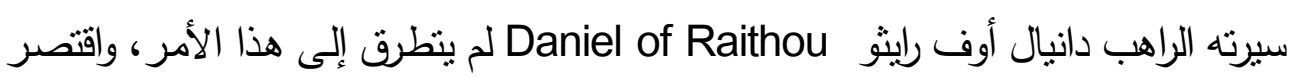

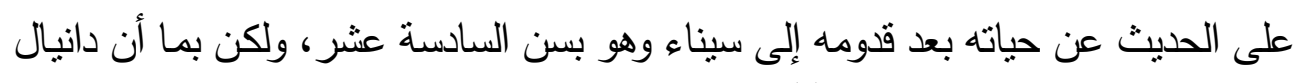

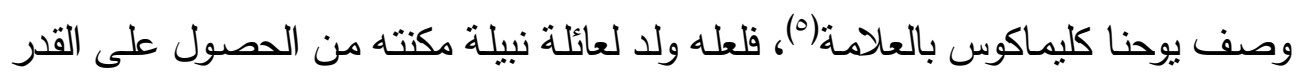

(1) Walter D. Ward, The Mirage of the Saracen : Christians and Nomads in the Sinai Peninsula in Late Antiquity, University of California Press, California , 2015, p.38, p.114 .

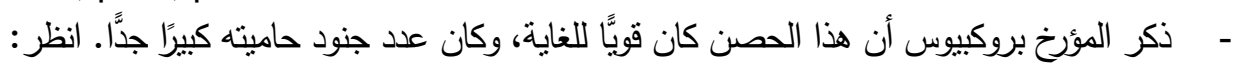
Procopius, The Buildings of Justinian, trans. A. Stewart, London ,1888,

p.147.

$\left(^{2}\right)$ Evagrius, Ecclesiastical History, p. 262.

( 3 )Anastasius of Sinai, Tales of The Sinai Fathers, in History and Hagiography from the Late Antique Sinai, trans. D. Caner, Liverpool University Press, Liverpool, 2010, p.175.

(4) Anastasius of Sinai, Tales of The Sinai Fathers, p.183.

$\left({ }^{5}\right)$ Daniele Rhaitheno, vita St. Joannis Scholastici Climaei, ed. Migne, in P.G.,vol.88, 1864, (cols.595-610), col.596. 
الكافي من التعليم، والذي يظهر في أسلوبه الكتابي الغني بـالمفردات اللغويـة والتشبيهات الأدبية.

وعلى أية حال فبمجرد وصول يوحنا كليماكوس - وهو بسن السادسة عشر - إلى سيناء

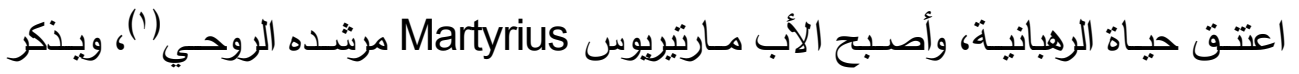

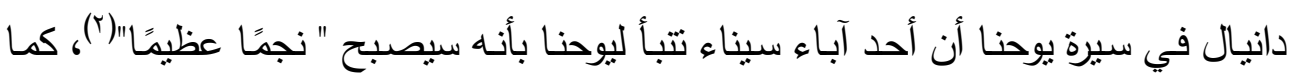

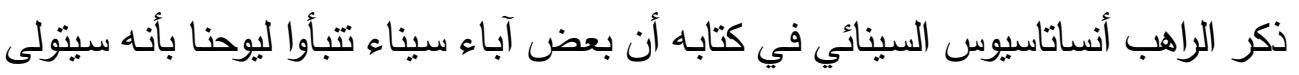

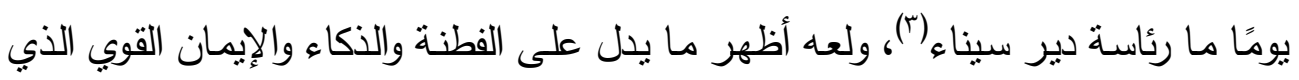
جعلهم يتتبؤون له بذللك.

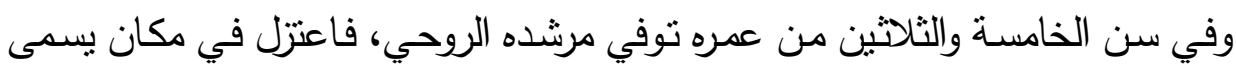

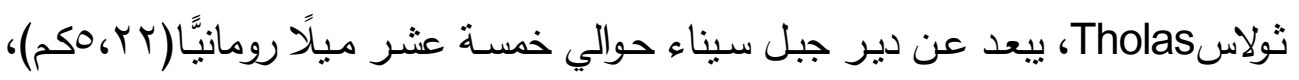

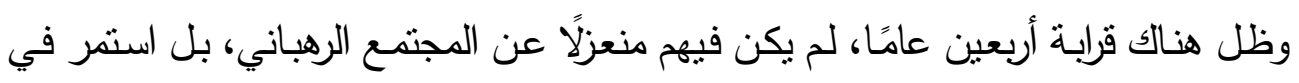

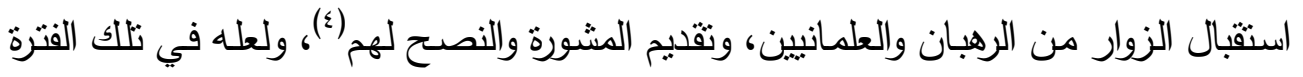

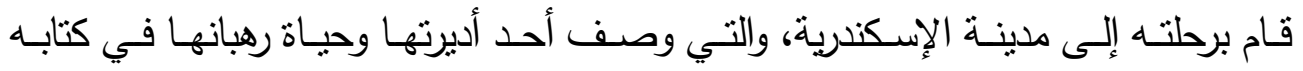

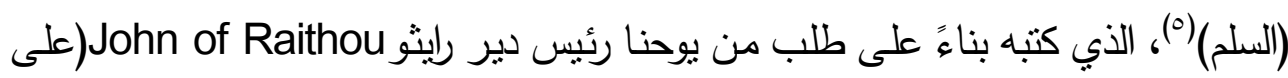

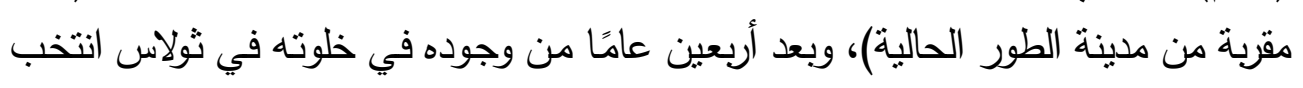

(1) Daniele Rhaitheno, vita, cols. 597,600.

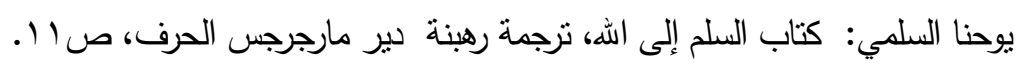

Andrey Kordochkin, John Climacus and the spiritual tradition of the IV-Vii centuries, Durham theses, Durham University, 2003, p.18.

( $\left.{ }^{2}\right)$ Daniele Rhaitheno, vita, col.608.

(3)Anastasius of Sinai, Tales of The Sinai Fathers, p.181.

$\left({ }^{4}\right)$ Daniele Rhaitheno, vita, col.597.

Andrey Kordochkin, John Climacus, p.19.

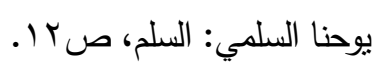


رئيسًا لدير جبل سيناء(")، وإن كنا لا نعرف المدة التي قضاه في هذا المنصب، إلا إنه نال

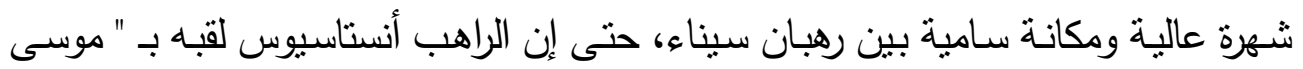

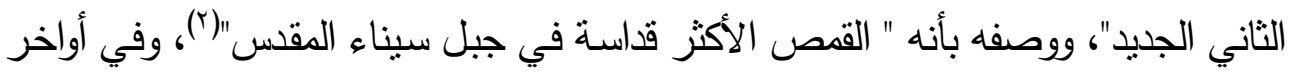

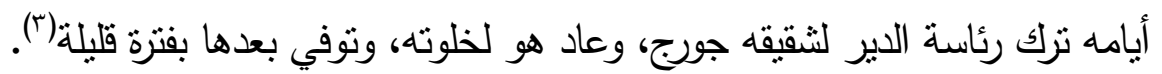

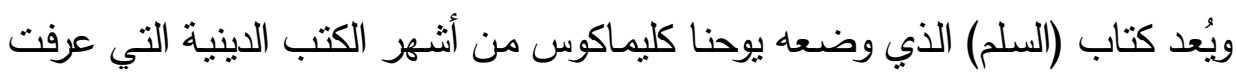

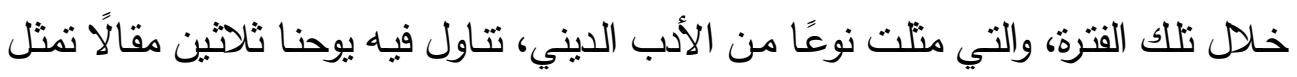

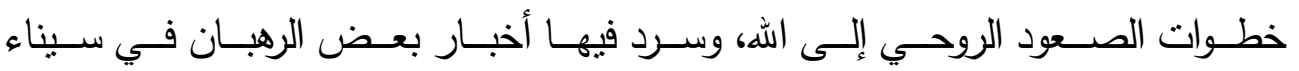

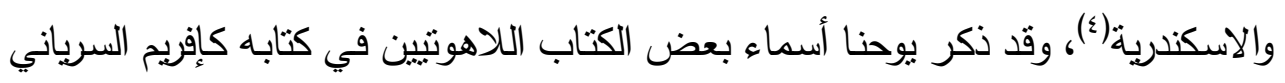
Ephrem

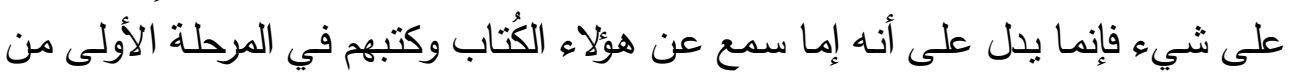

(1) Anastasius of Sinai, Tales of The Sinai Fathers, p.181.

Cf.also, Andrey Kordochkin: John Climacus, p.19.

$\left(^{2}\right)$ Anastasius of Sinai, Tales of The Sinai Fathers, pp.175,183.

(3) Daniele Rhaitheno, vita , col.609; Anastasius of Sinai, Tales of The Sinai

Fathers,pp.183-84.

Cf. also, Andrey Kordochkin: John Climacus, p.19.

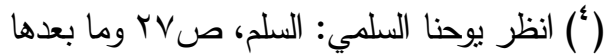

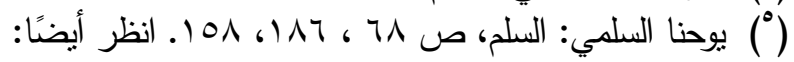

Andrey Kordochkin: John Climacus, p.20.

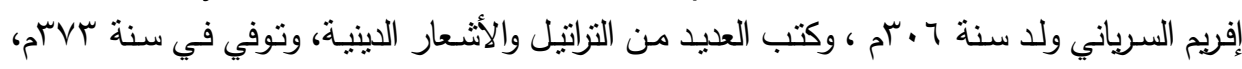

$$
\text { اللمزيد انظر: }
$$

$=$ Christopher Loveless, Strange Eventful History the story of the Saints of the church of England,2012, p.98-9.

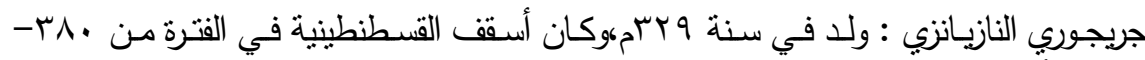

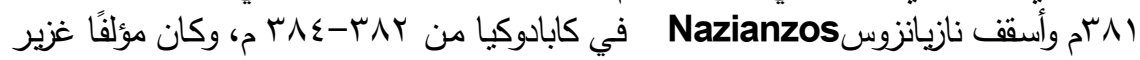

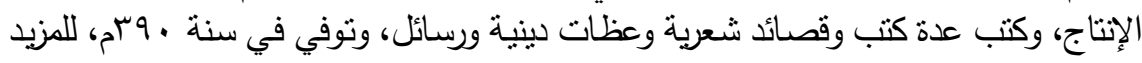

Kazhdan and Others, O.D.B,vol.2, pp.880-81. 
حياته، أو عن طريق وصول تلك الكتب إلى سيناء وتداولها بين أيدي الرهبان، وفي هذه

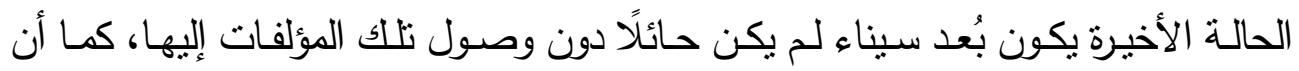
الرهبان هناك لم يكونوا منعزلين تمام الانعزال عن العالم الخارجي.

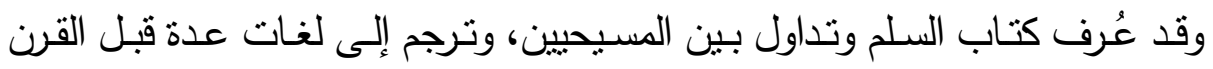

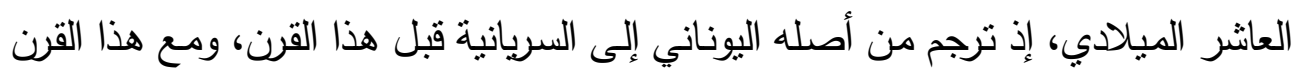

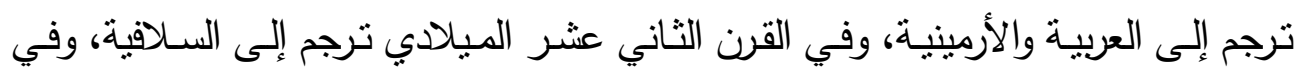

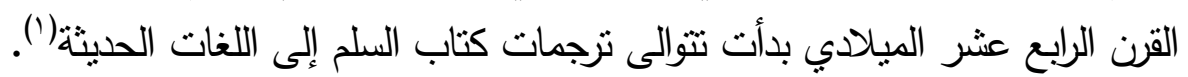

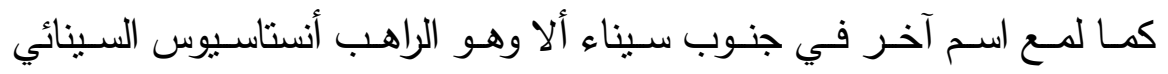
Anastasius of Sinai

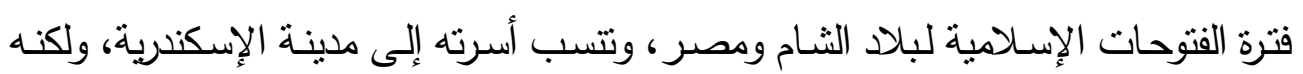

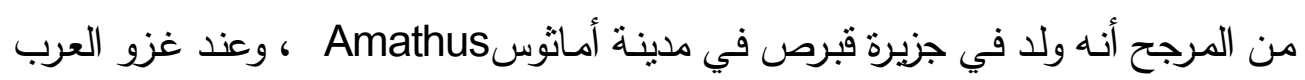

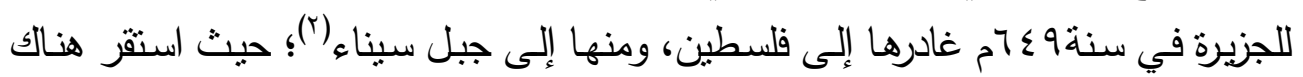

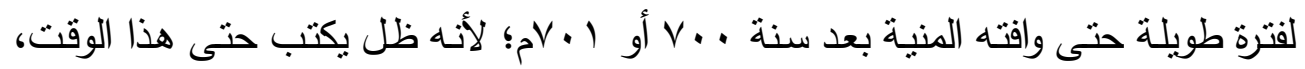

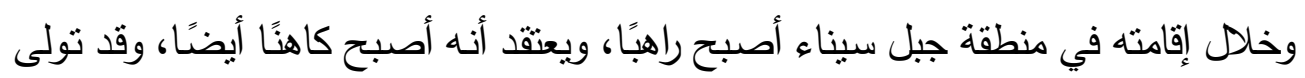

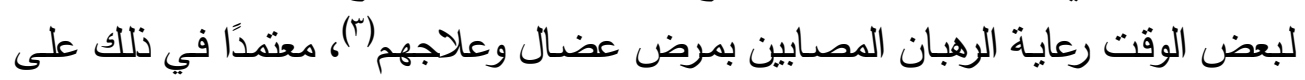

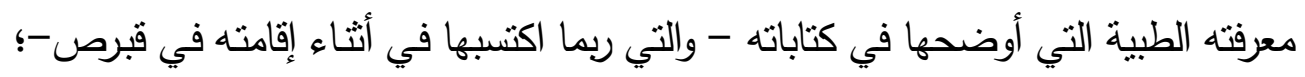

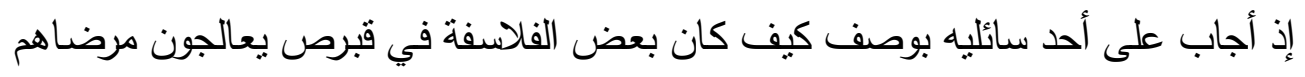

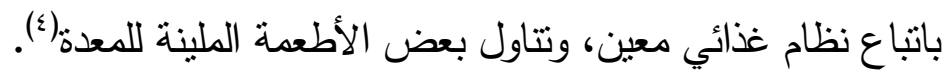

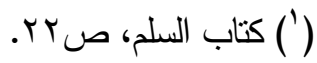

$\left(^{2}\right)$ Clement Kuehn, Anastasius of Sinai: Biblical Scholar, in B.Z., vol.103, 2010, (pp.55-81), p.55.

$\left({ }^{3}\right)$ David Thomas and others, Christian-Muslim Relations :A Bibliographical History (600-900), 16 vols. Brill, Leiden ,2009, vol.1, p.193.

(4) Anastasius Sinaita, Interrogationes et Responsiones, ed.Migne, in P.G., vol.89,1865, cols.732-33. 
وقد تنقل أنستاسيوس في منطقة جنوب سيناء؛ إذ عاش مدة ثلاتث سنوات في أرسيلايو

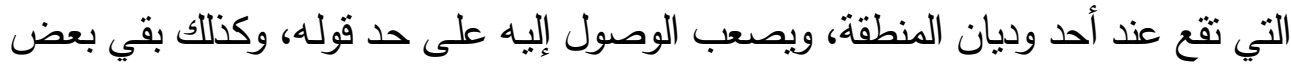

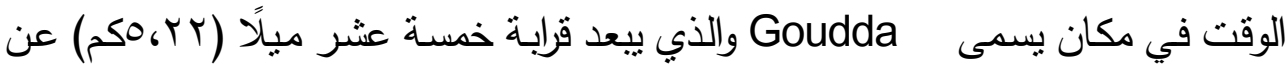

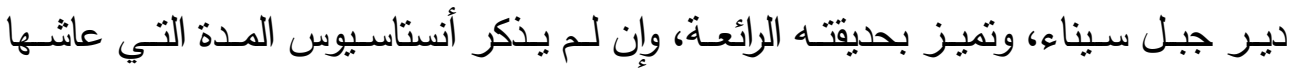

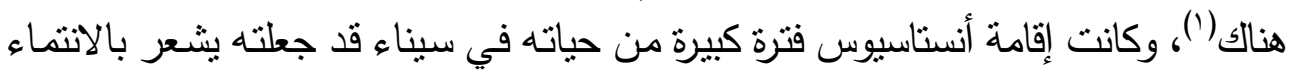

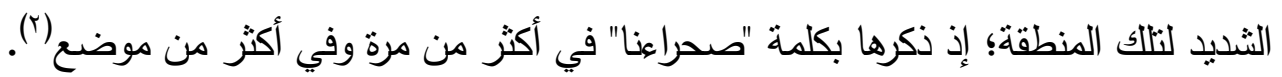

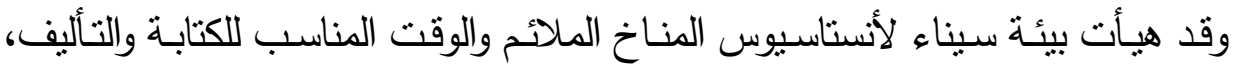

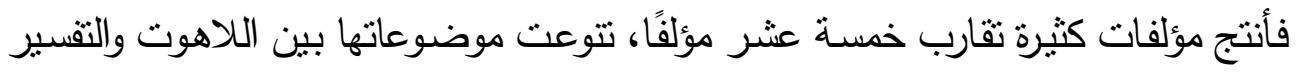

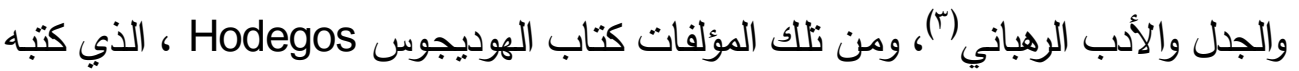

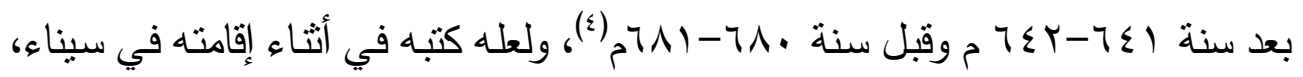
واهنم أنستاسيوس فيه بشكل أساسي بدحض البداع، وتطرق فيه إلى العقيدة الإسـامية،

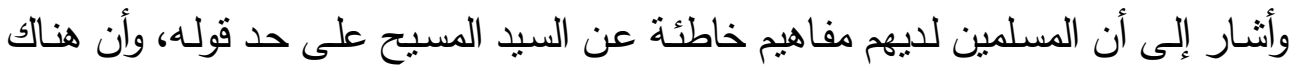
خلافات لاهوتية حقيقية بين المسيحيين والمسلمين (o).

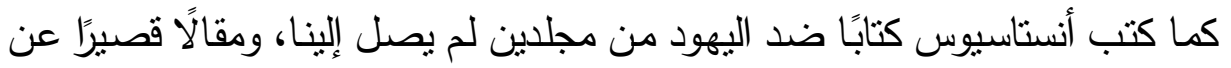

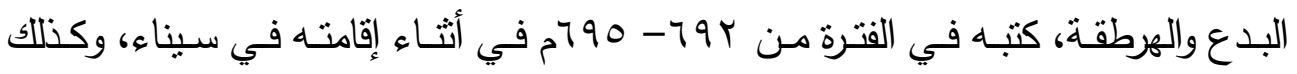

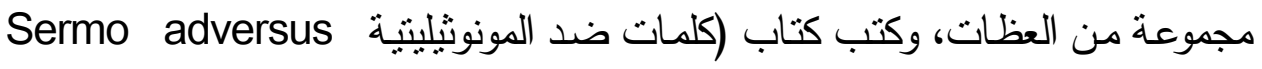

$\left({ }^{1}\right)$ Anastasius of Sinai, Tales Sinai Fathers, p.172, n. 2, pp.183, 190.

(2) Anastasius of Sinai, Tales Sinai Fathers, pp.181, 184,188,196.

$\left({ }^{3}\right)$ David Thomas and others, Christian-Muslim Relations, vol.1, p.194.

$\left({ }^{4}\right)$ John Haldon, "The works of Anastasius of Sinai. A key source for the history of seventh-century east Mediterranean society and belief ", in The Byzantine and early Islamic Near East. I. Problems in the literary source material, ed.A. Cameron and L.I. Conrad, the Darwin Press, Princeton, 1992, (pp.107-47), p.113.

$\left({ }^{5}\right)$ David Thomas and others, Christian-Muslim Relations, vol.1, p.196. 
Monotheletas

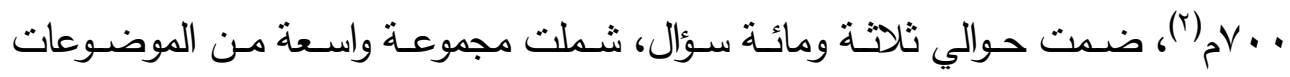

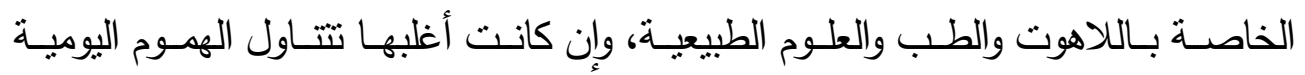
للمسيحيين(")، وقد أضافت أجوبة أنستاسيوس موضوعات جديدة عما كتبه الرهبان السابقون

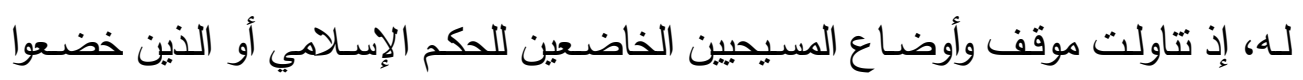

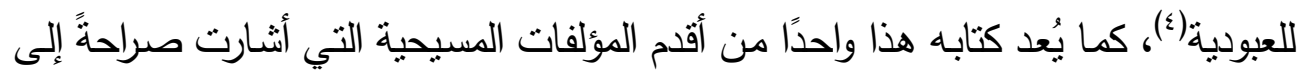
بعض المعتقدات الإسلامية، كرفض الثبطان الخضوع لآدم (ه). هذا إلى جانب ما كتبه أنستاسيوس السينائي عن حكايات آباء سيناء التي تمثل الجانب

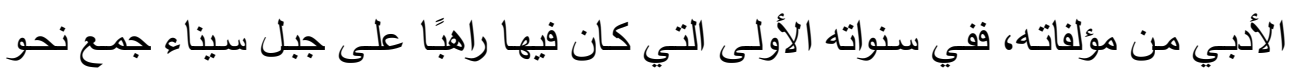
تسعة وثلاثثين قصة عن الرهبان والنساك الذين يعيثون في الصحاري حول جبل سيناء في

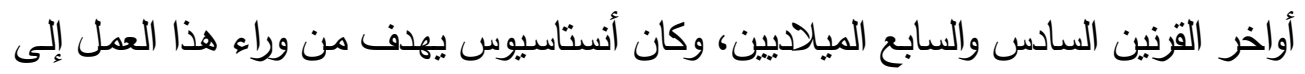

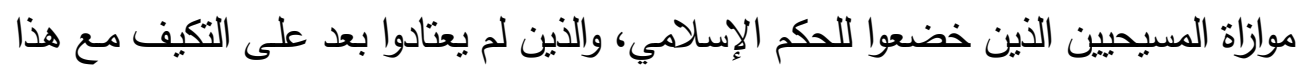

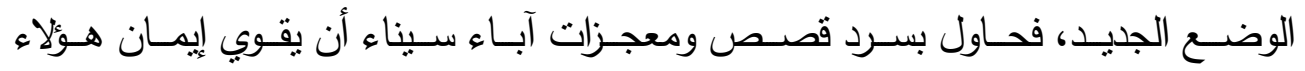
المسيحيين، وينثيهم عن الارتداد عن المسيحية، كما توفر قصصـه تلك أدلة وثائقية لتاريخ

( $\left.{ }^{1}\right)$ John Haldon, works of Anastasius of Sinai, pp.112-13.

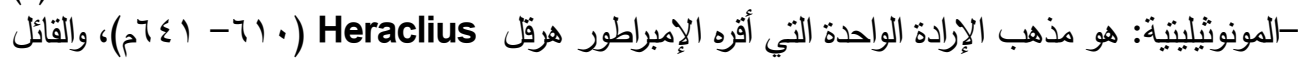

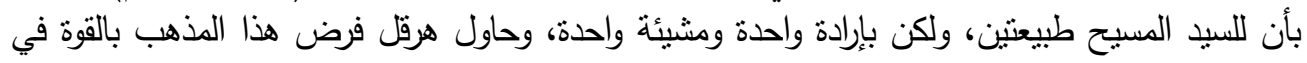

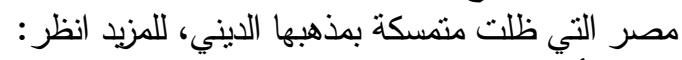

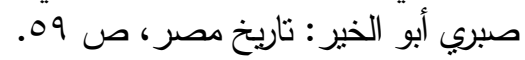

$\left({ }^{2}\right)$ John Haldon, works of Anastasius of Sinai, p.120.

( $\left.{ }^{3}\right)$ Anastasius Sinaita, Interrogationes, cols.711- 824,

Cf. also, David Thomas and others, Christian-Muslim Relations, vol.1, p.201.

$\left({ }^{4}\right)$ John Haldon, works of Anastasius of Sinai, p.130.

$\left({ }^{5}\right)$ David Thomas and others, Christian-Muslim Relations, vol.1, p.201. 


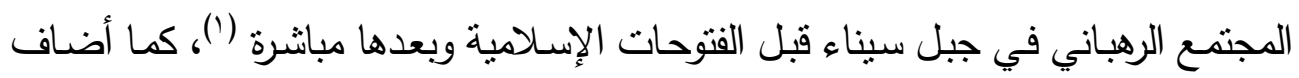

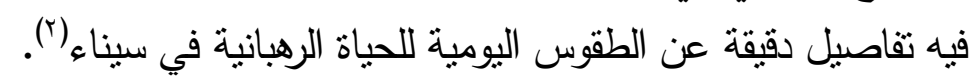

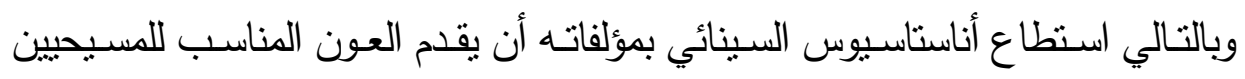

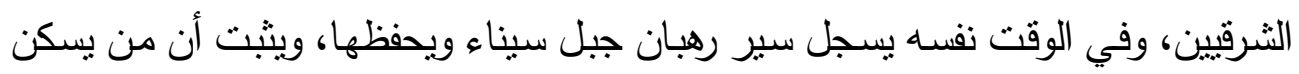

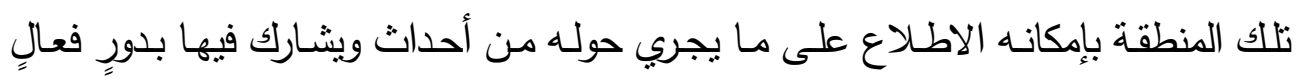
ومؤثرٍ .

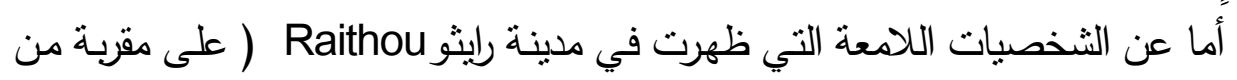

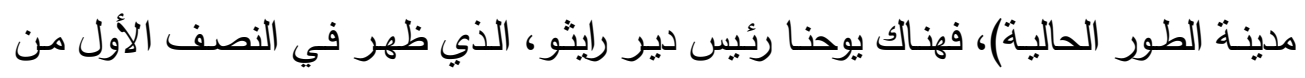

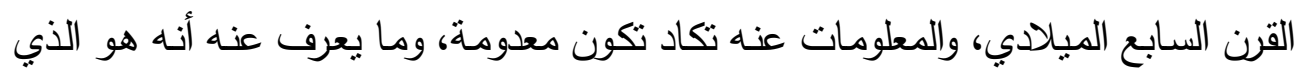

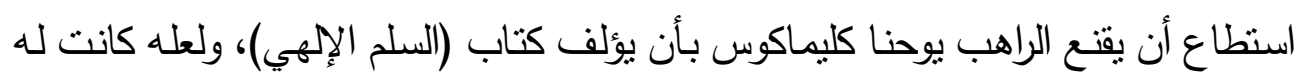

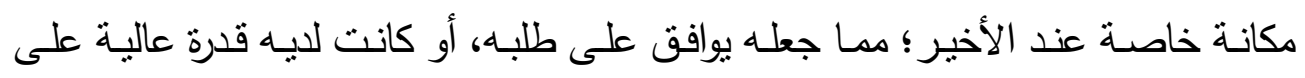

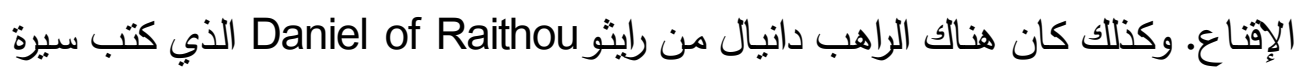

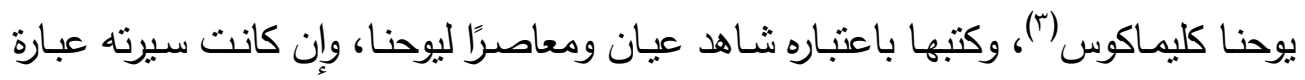

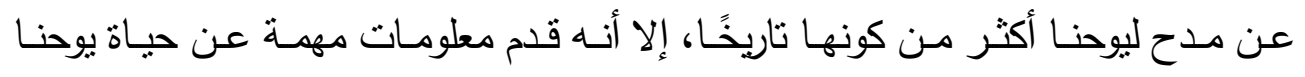

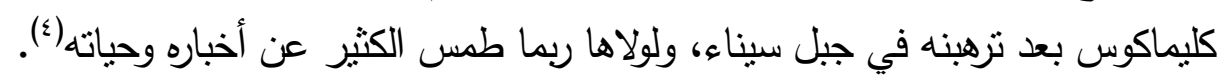

\section{وفي النهاية أجمل ما توصلت إليه الاراسة في الآتي:}

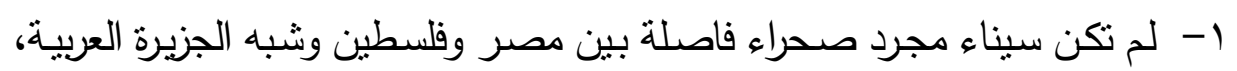

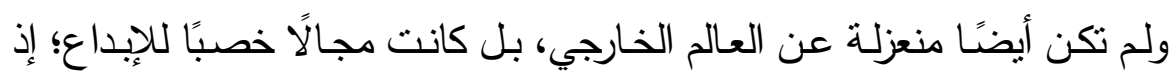

( ${ }^{1}$ ) David Thomas and others, Christian-Muslim Relations, vol.1, p.198.

( $\left.{ }^{2}\right)$ Anastasius of Sinai, Tales of The Sinai Fathers, p.172

(3) Daniel Caner, History and Hagiography from the Late Antique Sinai, trans.

D. Caner, Liverpool University Press, Liverpool, 2010., p.37.

Daniele Rhaitheno, vita, cols.595-610.

( ) أظر سيرة يوحنا كليماكوس التي كنبها دانيل أوف رايثو: 
أناحت الفرصة لساكنيها ليبدعوا ويألفوا في هدوءٍ وسكينةٍ، ويشاركوا في الوقت نفسه

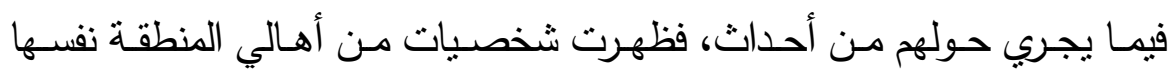

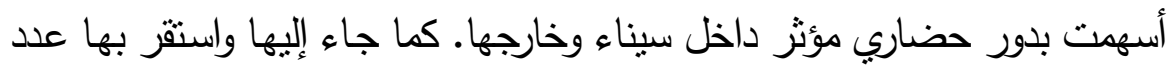

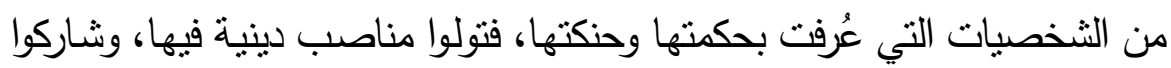
في حضور المجامع الدينية التي عقدت خارجها، ودونوا مؤلفات ظلت بكات باقية لتندل

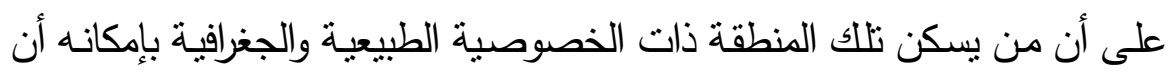

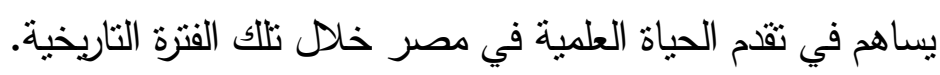

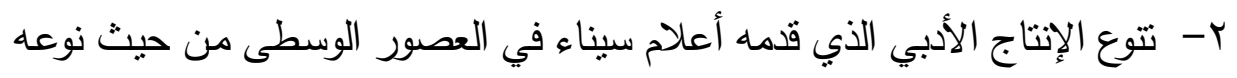

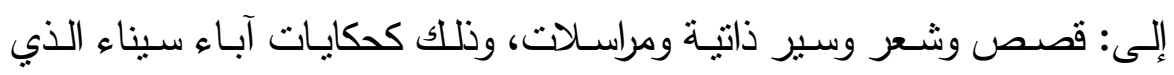

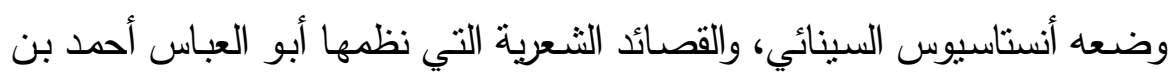
إبراهيم بن الفتح العريثي وحفيده، وسيرة القديس يوحنا كليماكوس التي كتبها دانيال من رايثو، ومراسلات إيبيدور البيلوزي التي بلغ علئ عددها ألفي رسالة.

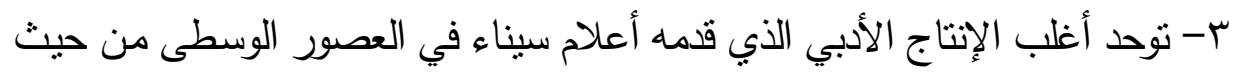

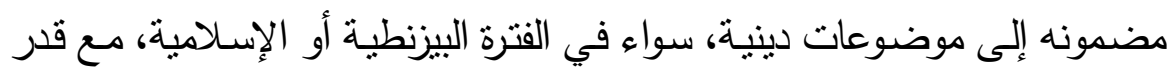

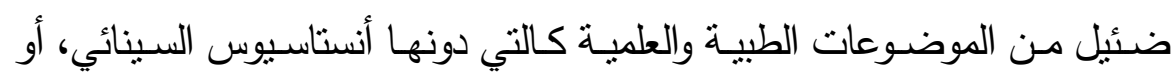
الموضوعات السياسية والاجتماعية كبعض مراسلات إيسيلور البيلوزي .

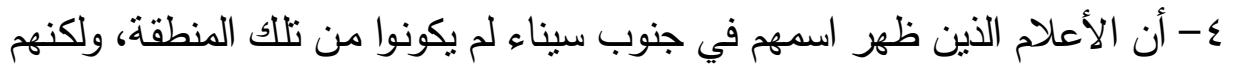

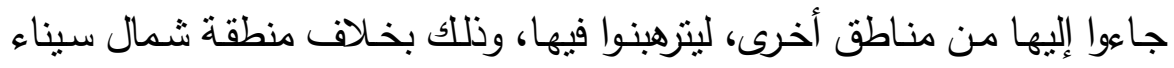
التي ظهر فيها أعلام ولدوا وتربوا في مدن نلاك المنطقة الساحلية.

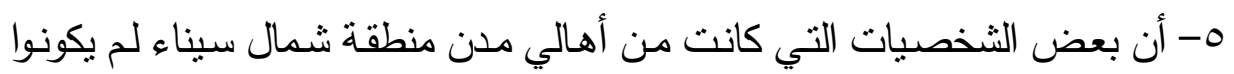

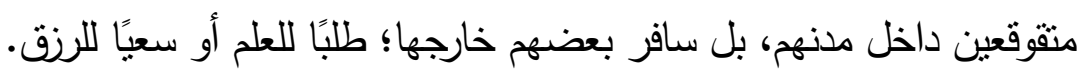




\section{قائمة بالمختصرات الواردة في البحث}

B.Z. Byzantinische Zeitschrift

O.D.B. The Oxford Dictionary of Byzantium

P.G. Patrologiae Graeca

\begin{tabular}{|c|c|c|c|c|}
\hline الدور الذي قام به & الفترة الزمنية & المكانة أو & ظهرينة دوره التي & الثخصية \\
\hline 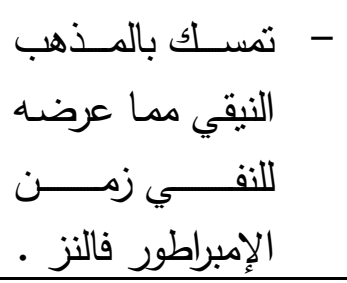 & قبل 0بr & رينوكورورا & رينوكورورا & ميلاس \\
\hline 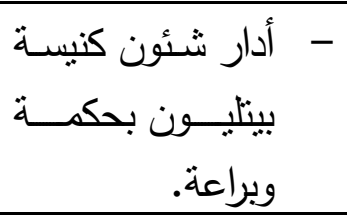 & 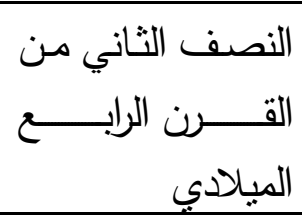 & بيتليون & بيتليون & أجاكس \\
\hline - لثقلى الأسققية خلفًا & بعد 70سم & رينوكورورا & رينوكورورا & سولون \\
\hline 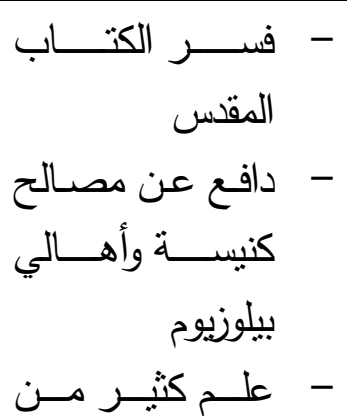 & 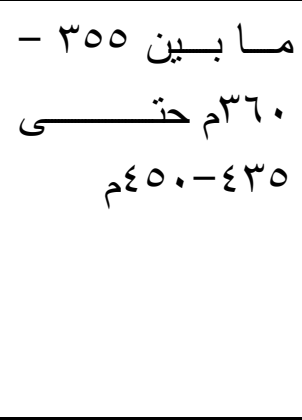 & وراهن & شيلوزيوم & البيلوزيـــــيليور \\
\hline
\end{tabular}




\begin{tabular}{|c|c|c|c|c|}
\hline 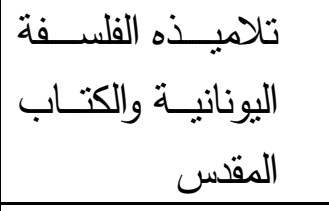 & & & & \\
\hline - من البارزين & 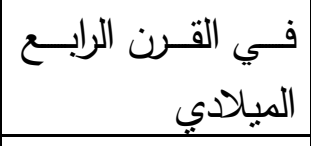 & رئيس دير & رينوكورورا & ديونيسيوس \\
\hline 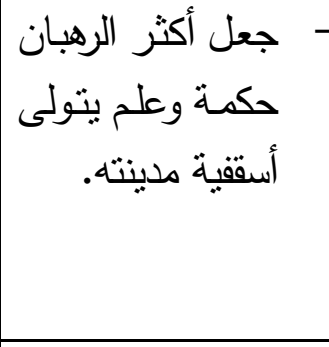 & بداية القرن الخامس & سلصي & رينوكورورا & هيركليون \\
\hline 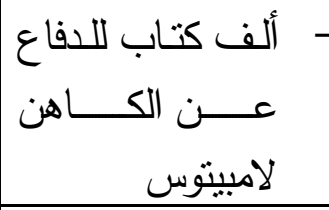 & 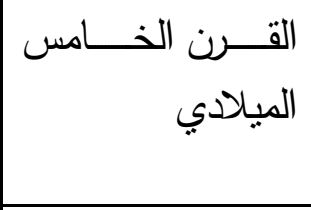 & رينوكورورا & رينوكورورا & ألفيوس الأول \\
\hline 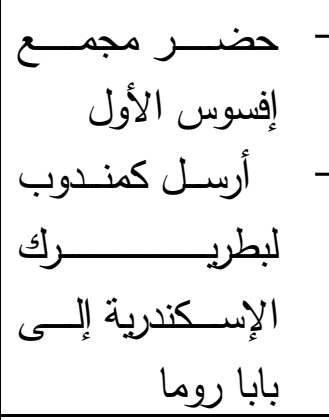 & م $2 \leqslant q-\varepsilon r)$ & رينوكورورا & رينوكورورا & هيرموجينيس \\
\hline 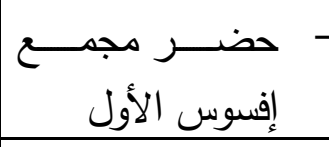 & 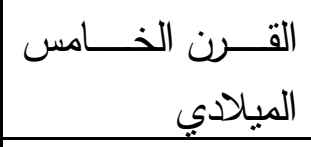 & أوستراكين & أوستراكين & أبراهام \\
\hline - إفسوس الأول & 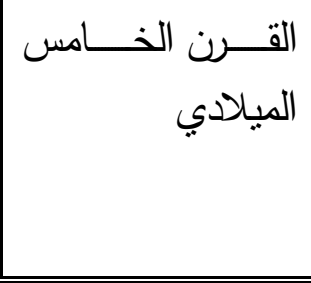 & كاسيوم & كاسيوم & لامبيتوس \\
\hline
\end{tabular}




\begin{tabular}{|c|c|c|c|c|}
\hline 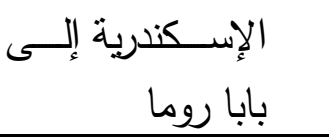 & & & & \\
\hline 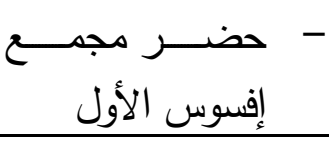 & 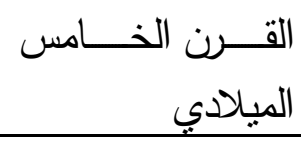 & بيلوزيون & بيلوزيوم & يوسيبييوس \\
\hline - - حضـــــر مجــــع & $2 \leqslant 0 .-\leqslant \leqslant 9$ & رينوكورورا & رينوكورورا & زينون \\
\hline - & الميلادي القــرن الخــــامس & أسقايوم & 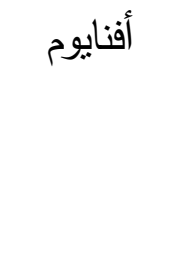 & هيراكيس \\
\hline 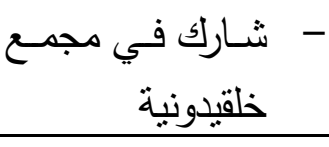 & 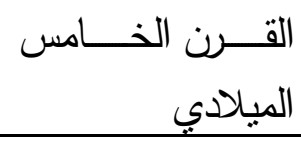 & أسقق جيرا & جيرا & ستيفانوس \\
\hline 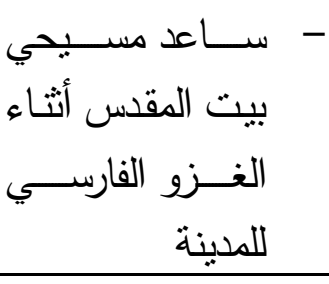 & 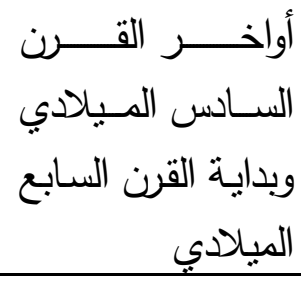 & أسقق & رينوكورورا & جريجوريوس \\
\hline 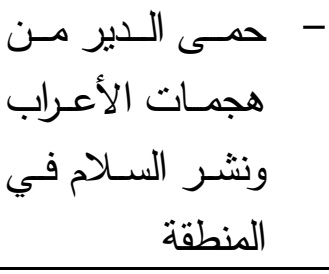 & 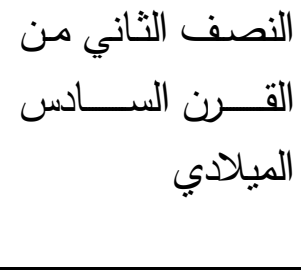 & جئ سينس دير & جبل سيناء & الأنطاكي \\
\hline - ألف كتاب السلم & 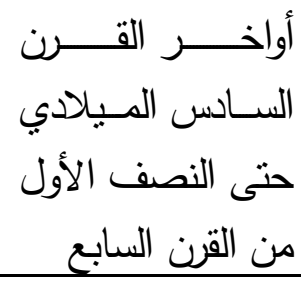 & ورئيس دير & جبل سيناء & 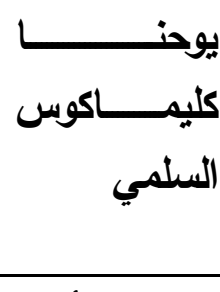 \\
\hline - أقن لـــــع يوحنـــــا & النصـف الأول مـن & رئيس دير & رايثت & يوحنــــــا أوف \\
\hline
\end{tabular}




\begin{tabular}{|c|c|c|c|c|}
\hline كتيبـاكوس بتـأليف & 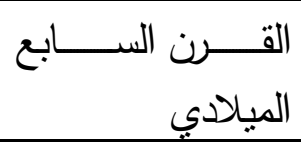 & رايثو & & رايثو \\
\hline 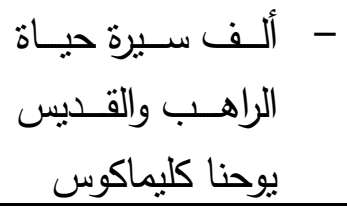 & 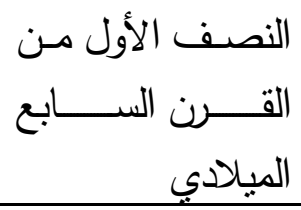 & راهب & رايثو & دايثو \\
\hline 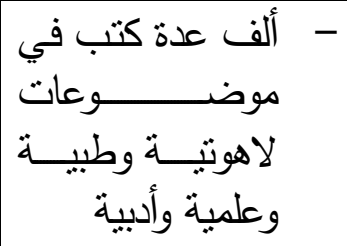 & 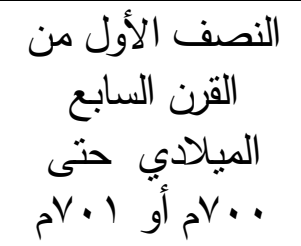 & راهب & جبل سيناء & أناستاسيوس السيني \\
\hline - مل حدث عن الفقاء والرواة فيار & قبل سنة r ع اهـ| & راوي & من الفرما & 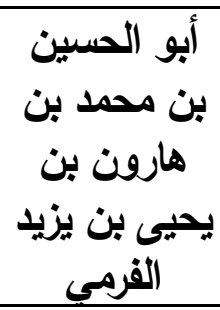 \\
\hline - كبار المشايخ الحديث عن & 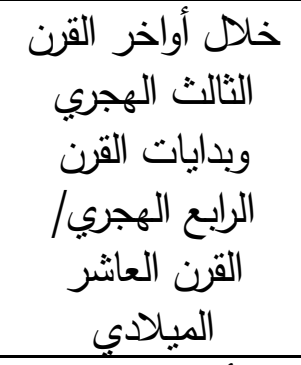 & راوي & من الفرما & "أبو حفص بن زنق بن \\
\hline - - تُعلم الفقه والحديث & 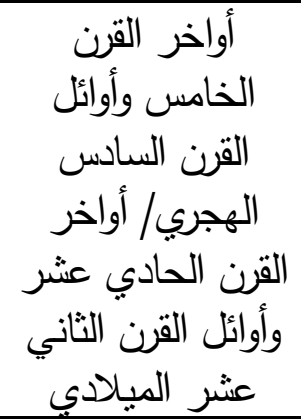 & وشاعر & من العريش & 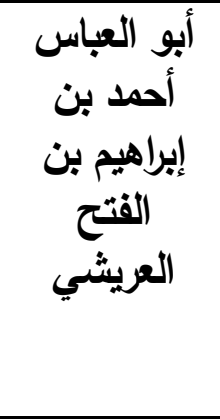 \\
\hline
\end{tabular}




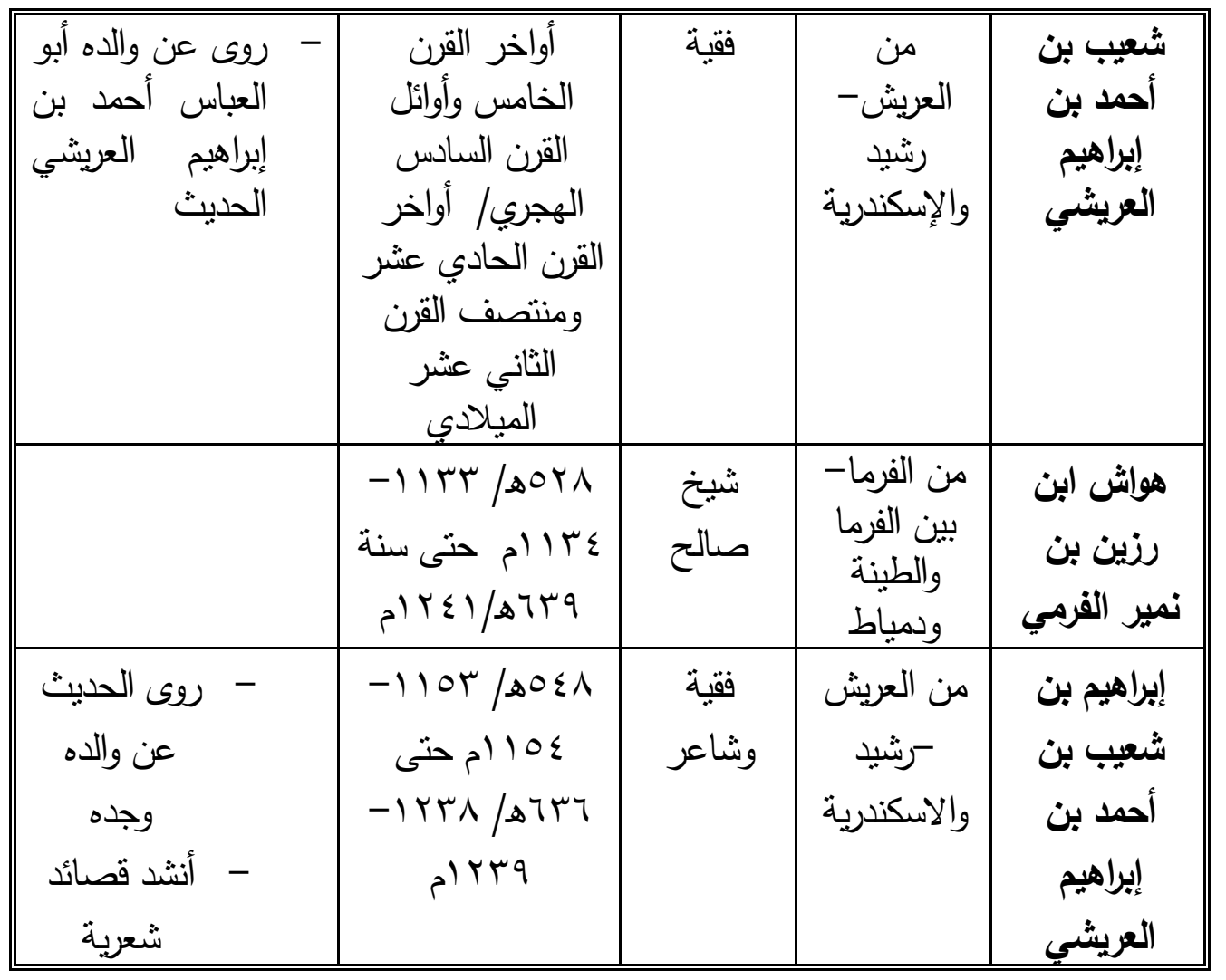

خريطة مدن سيناء في العصر البيزنطي

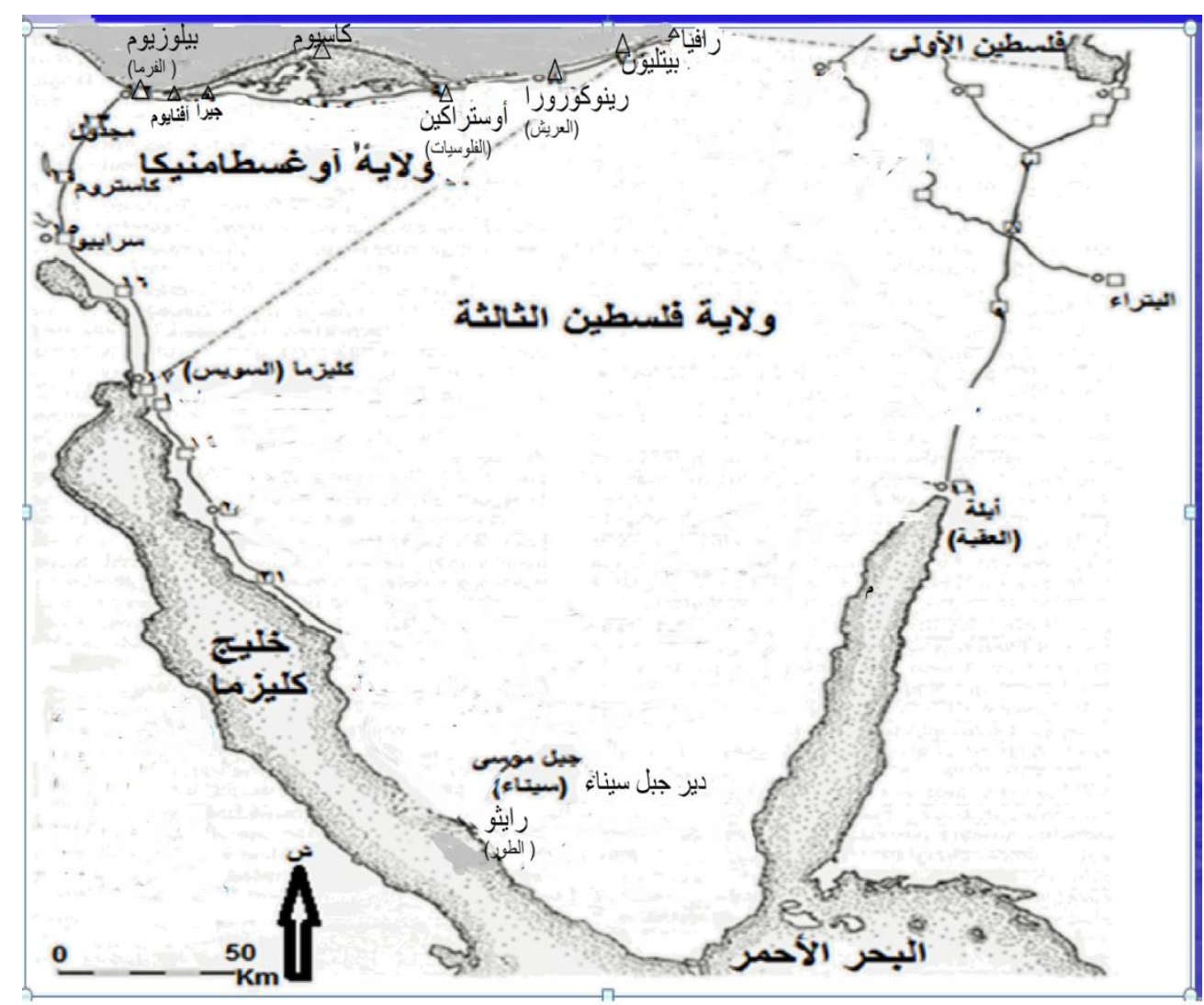


نقلًا عن : محمد زليد عبد الله: سيناء مقصدًا للهاربين، ص • I . .

- Irr 


\section{قائمة المصادر والمراجع}

\section{أولًا: المصادر الأجنيةة:}

The Acts of the Council of Chalcedon،

3vols.، Trans. Richard Price and Michael Gaddis، Liverpool

University Press، Liverpool، 2005.

Anastasius of Sinai،

Tales of The Sinai Fathers، in History and Hagiography from the Late Antique Sinai، trans. D. Caner، Liverpool University Press، Liverpool، 2010.

Anastasius Sinaita،

Interrogationes et Responsiones، ed.Migne، in P.G.، vol.89،1865.

\section{Daniele Rhaitheno،}

vita St. Joannis Scholastici Climaei، ed. Migne، in

P.G.،vol.88، 1864، (cols.595-610)

\section{Epiphanius of Salamis،}

The Panarion of Epiphanius of Salamis Book I (Sects 1-46)، trans . F. Williams، 2nd، Brill، Leiden، 2009.

\section{Evagrius،}

The Ecclesiastical History of Evagrius Scholasticus، Trans.

M. Whitby، Liverpool Unviersity Press، Liverpool ،2000

\section{Georgii Cyprii،}

Descriptio Orbis Romani، ed.H. Gelzer، Lipsiae،1790.

\section{Hieroclis،}

Synecdemvs Et Notitlae Graecae Episcopatvvm، ed. G.

Parthey ، Berolini، 1866. 
Isidori Pelusiotae،

Sancti Isidori Pelusiotae de interpretatione divina Scriptura.

Epistolarum، ed. Auctior et Emendatior، Venetiis ،1745

Polybii Episcopi Rhinocorurorum،

Vita Sancti Epiphanii، ed، Migne، in P.L.،vol.

41،1863،(cols. 37-114).

\section{Procopius،}

The Buildings of Justinian، trans. A. Stewart، London ،1888،

\section{Severus Patriarch of Antioch،}

The Sixth Book of the Select Letters of Severus Patriarch of Antioch in the Syriac Version of Athanasius of Nisibis، 2 vols. trans. E. Brooks، Oxford، 1903.

\section{Sophronius ،}

"The Life of Our Holy Father John The Father " in From Three Byzantine Saints: Contemporary Biographies of St. Daniel the Stylite، St. Theodore of Sykeon and St. John the Almsgiver ، trans. Elizabeth Dawes، and introductions and notes by Norman H. Baynes، London، 1948.

\section{Sozomen،}

The Ecclesiastical History of Sozomen ، tr. E. Walford، London، 1855.

\section{Sozomenus،}

Church History from 323-425، in Nicene and Post-Nicene Fathers: Second Series Socrates، Sozomenus Church Histories، Tras. C. Hartranft، 14 vols.، ed. Philip Schaff، New York، 2017، vol. 2. 


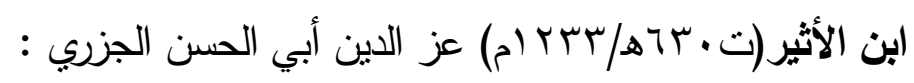

اللباب في تهذيب الأنساب، اجن، تحقيق عبد اللطيف حسن عبد الرحمن، دار

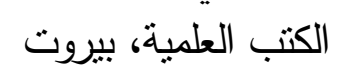

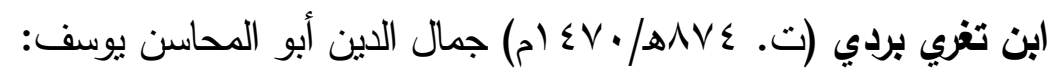

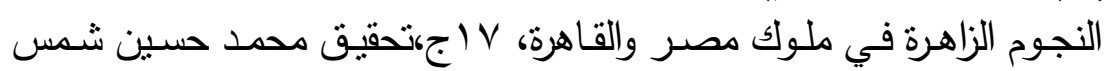

$$
\text { الدان، دار الكثب العلمية، بيروت. }
$$

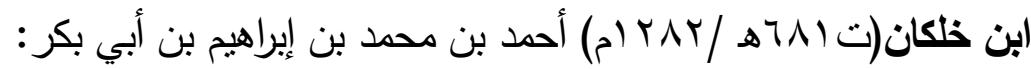

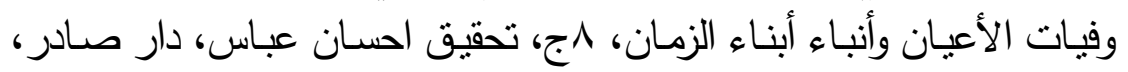

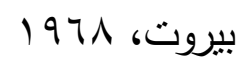

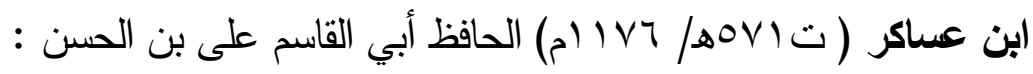

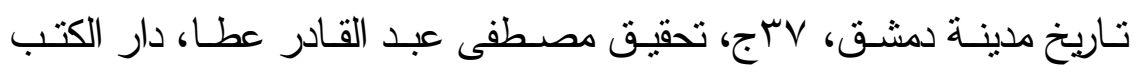

$$
\text { العلمية، بيروت. }
$$

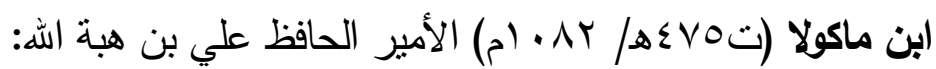

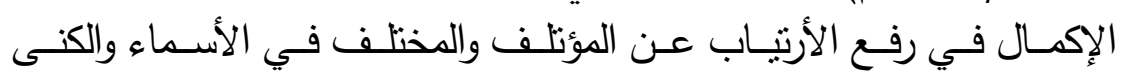

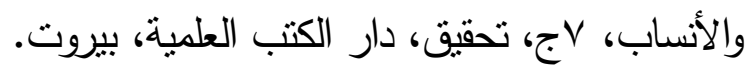

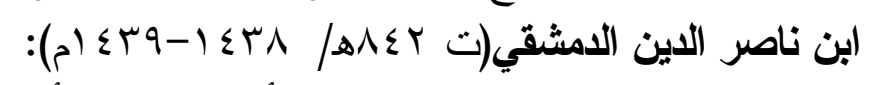

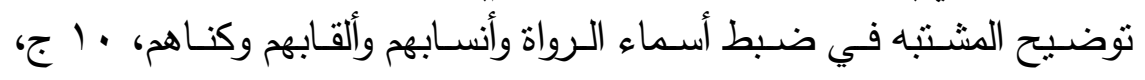

$$
\text { تحقيق محمد نعيم العرقسوسي، مؤسسة الرسالة. }
$$

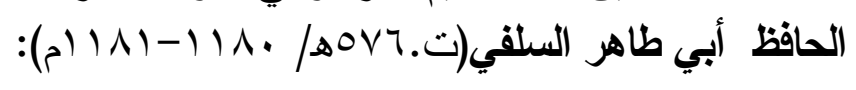

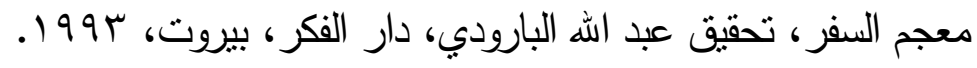

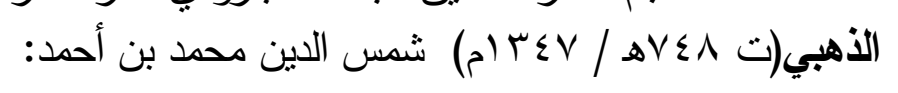

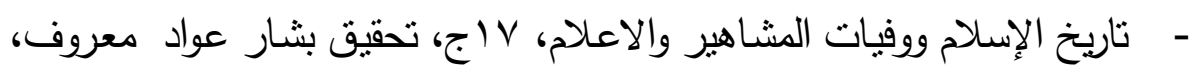

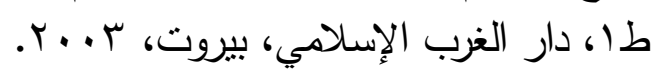

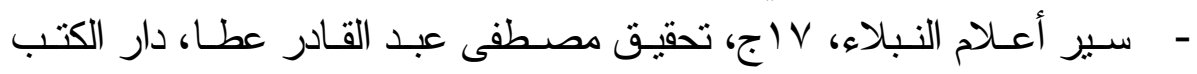

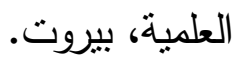




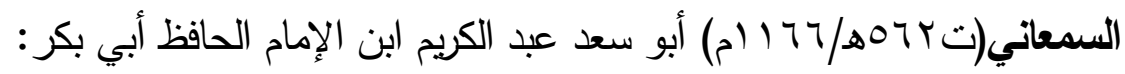

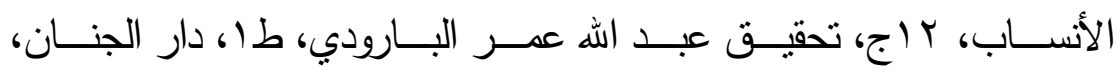

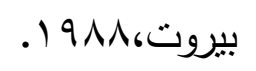

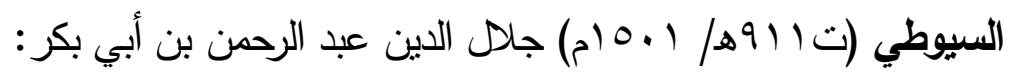

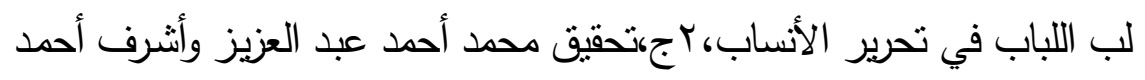

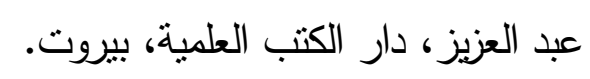

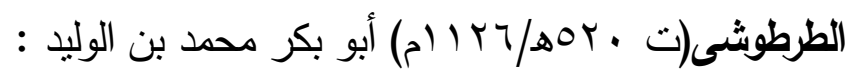

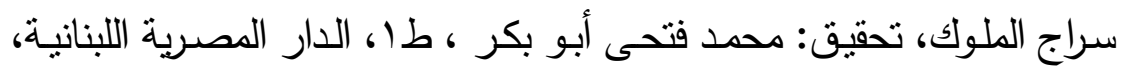
القاهرة ، ع ع 199.

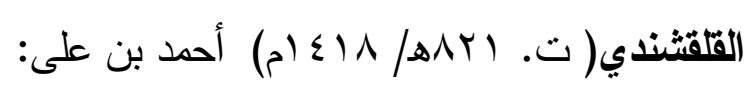

صبح الأعثى في صناعة الإنثا، 0 اجه، تحقيق محمد حسين شئ شمس الدين، دار

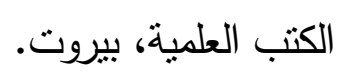

\section{مخطوط السنكسار القبطي اليعقويي:}

تعليق ميخائيل مكسي إسكندر، هارموني للطباعة.

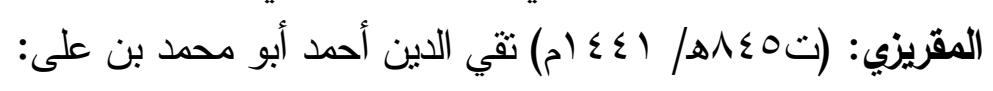

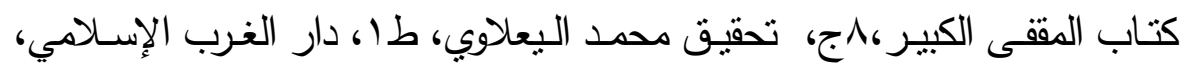

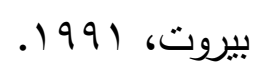

المنذري(ت 707هـ/ T01 ام ) زكي الدين أبو محمد عبد العظيم بن عبد القوي:

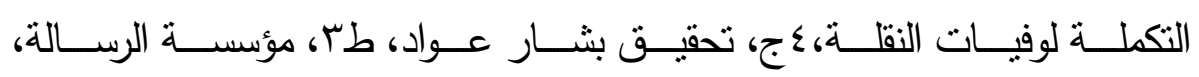

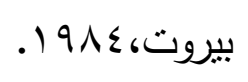

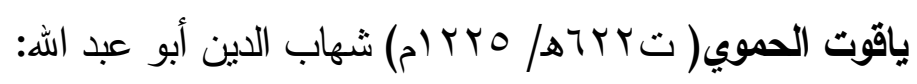

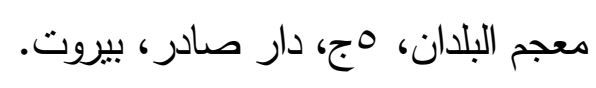

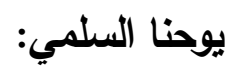

كتاب السلم إلى الله، تزجمة رهبنة دير مارجرجس الحرف. 
Christopher Loveless،

\section{ثُاثثًا: المراجيع الأجنيسة:}

Strange Eventful History the story of the Saints of the church of England، 2012.

\section{Daniel Caner،}

History and Hagiography from the Late Antique Sinai، trans.

D. Caner، Liverpool University Press، Liverpool، 2010.

\section{David T. Runia،}

Philo and the Church Fathers: A Collection of Papers، Brill، Leiden، 1995.

\section{David Thomas and others،}

Christian-Muslim Relations :A Bibliographical History (600-900)، 16 vols. Brill، Leiden ،2009.

\section{Frank R. Trombley،}

Hellenic Religion and Christianization: C. 370-529، 2vols.، 2nd، Brill Academic Publishers، Boston ، 2001.

\section{Herbert Verreth،}

The Northern Sinai From The 7th Century BC Till The7th Century AD.A Guide to The Sources ، 2vols. ، Leuven، 2006.

Irfan Shahid,

Byzantium and the Arabs in the Sixth Century، 2vols.، Dumbarton Oaks، America، 1995. 


\section{John Haldon،}

"The works of Anastasius of Sinai. A key source for the history of seventh-century east Mediterranean society and belief "، in The Byzantine and early Islamic Near East. I. Problems in the literary source material، ed.A. Cameron and L.I. Conrad ، the Darwin Press، Princeton، 1992، (pp.107-47).

\section{Kazhdan and Others،}

O.D.B، 3 Vols ، Oxford University Press ، Oxford ، 1991.

\section{Lillian Larsen،}

"The Letter Collection of Isidore of Pelusium" ، in Late Antique Letter Collections: A Critical Introduction and Reference Guide، ed. C.sogno ، B.Storin \& E.Watts، University of California Press، 2017،( pp.286-308).

\section{Lina Eckenstein ،}

A History of Sinai، Reprint، Cambridge University Press، Cambridge، 2018.

\section{Madalina Toca،}

"Isidore of Pelusium's Letters to Didymus the Blind"، in Studia Patristica vol.XCVI Papers presented at the Seventeenth International Conference on Patristic Studies held in Oxford 2015، ed. M. Vinzent، Peeters، Leuven ، 2017،( pp.325-332).

\section{Madalina Toca \& Johar Leemans ،}

"The Authority of a 'Quasi-Bishop:Patronage and Networks in the Letters of Isidore of Pelusium"، in Episcopal Networks in Late Antiquity: Connection and Communication Across Boundaries، ed. C. Cvetkovic and P. Gemeinhardt، Berlin، 2019. 


\section{Nicolas Laos،}

The Metaphysics of World Order: A Synthesis of Philosophy، Theology، and Politics، Pickwick Publications، Eugene، 2015.

\section{Pau Figueras،}

From Gaza to Pelusium، in Beer- Sheva، vol. 14، Ben-Gurion University of the Negev Press، 2000.

\section{Pierre Évieux،}

Isidore de Péluse ، Beauchesne، Paris، 1995.

\section{Walter D. Ward,}

The Mirage of the Saracen : Christians and Nomads in the Sinai Peninsula in Late Antiquity، University of California Press ، California ، 2015.

لابعًا: المراحع العربية والمعربة: جمال الاين الثيال :

أعلام الإسكندرية في العصر الإسلامي، مكتبة الثقافة الدينية، القاهرة، I . . . .

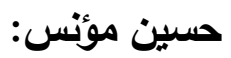

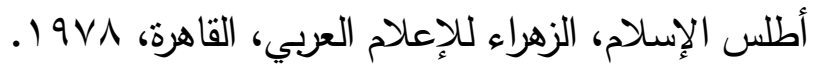

$$
\text { صبري أبو الخير: }
$$

تاريخ مصر في العصر البيزنطي،ط ب، عين للدراسات والبحوث الانسانية

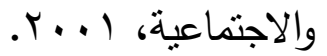

$$
\text { مجموعة الثرع الكنسي : ماعن }
$$

أو قوانين الكنيسة المسيحية الجامعة التي وضعها المجامع المسكونية والمكانية

المقسة، تزجمة حنانيا الياس كساب، طب، مطبعة النور ، بيروت، 1991 ـ 


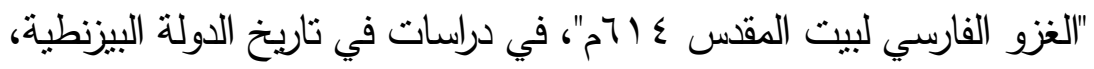

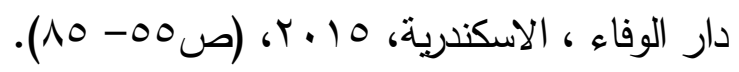

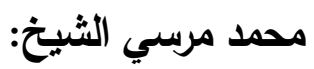

$$
\begin{aligned}
& \text { تاريخ مصر البيزنطية، } 1999 . \\
& \text { يسطس الأورشليمي: تئرئ }
\end{aligned}
$$

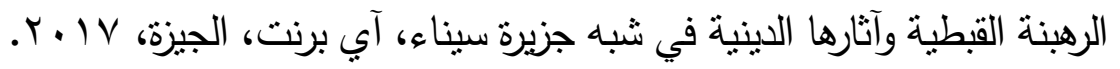

$$
\text { خامسًا: الرسائل العلمبة الأجنية: }
$$

\section{Andrey Kordochkin،}

John Climacus and the spiritual tradition of the Iv-Vii centuries، Durham theses، Durham University، 2003،

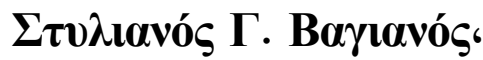

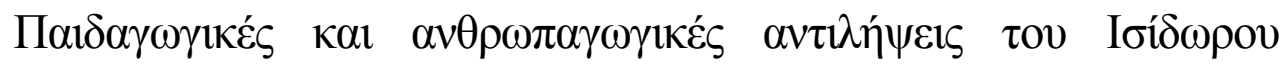

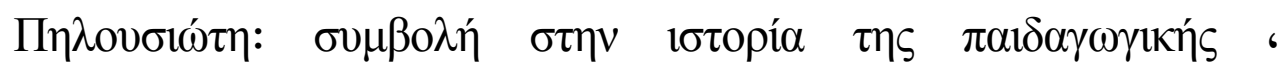

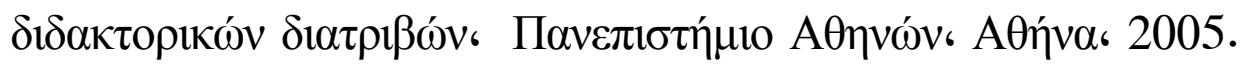

\section{ساديًا: الاوريات العلمية الأجنية:}

\section{Clement Kuehn،}

Anastasius of Sinai: Biblical Scholar، in B.Z.، vol.103، 2010، (pp.55-81).

$$
\text { سحمد زلايد عبدا: اللوريات اللهمية العربية: }
$$

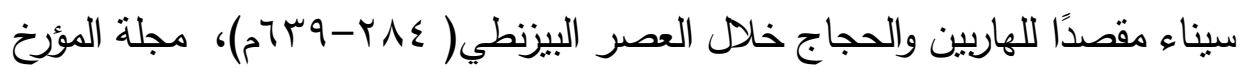

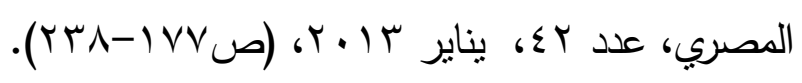

